Anales de Historia del Arte

ISSN: 0214-6452

http://dx.doi.org/10.5209/ANHA.57485

\title{
Melchor de Aguirre, cantero y arquitecto: corpus de portadas y retablos
}

\author{
José Antonio Díaz Gómez
}

Recibido: 26 de febrero de 2017 / Aceptado: 30 de mayo de 2017

Resumen. El presente artículo pretende poner de manifiesto el papel decisivo que el cantero y arquitecto Melchor de Aguirre, junto con su taller, jugó en el cambio de modelo de los retablos y las portadas del Barroco tardío andaluz. Con esta premisa, se realiza un estudio que contrasta los hallazgos de trabajos precedentes, así como los resultados propios derivados de las investigaciones desarrolladas sobre este conspicuo alarife como autor del Oratorio de San Felipe Neri de Granada.

Palabras clave: Melchor de Aguirre; arquitectura barroca; cantería; Andalucía; siglo XVII.

[en] Melchor de Aguirre, Stonemason and Architect: Corpus of Portals and Altarpieces

\begin{abstract}
This paper aims to highlight the decisive role played by the stonemason and architect Melchor de Aguirre, together with his worshop, in the change of model of altarpieces and façades during the late Baroque in Andalusia. With this premise, it's done a study that contrasts the findings of previous works, as well as the own results derived from the investigations carried out on this eminent architect as author of the Oratory of Saint Philip Neri in Granada.
\end{abstract}

Keywords: Melchor de Aguirre; Baroque Architecture; Stonework; Andalusia; $17^{\text {th }}$ Century.

Sumario. 1. Introducción. 2. La primera etapa (h. 1640 - 1670): el genio entre tinieblas. 3. La segunda etapa (1670 - 1679): el cantero egabrense. 4 . La tercera etapa (1679 - 1685): el maestro de canterías. 5. La etapa final (1685 - 1697): el maestro de maestros. 6. Conclusiones.

Cómo citar: Díaz Gómez, J.A. (2017): Melchor de Aguirre, cantero y arquitecto: corpus de portadas y retablos, en Anales de Historia del Arte 27, 139-167.

\section{Introducción}

La Castilla del siglo XIV asistió a los inicios de la gestación de una extensa saga de nobles maestros canteros, integrada por múltiples dinastías, que revistieron con orgullo los privilegios de la vizcainía y que se propagarían, a posteriori, por todos los territorios hispánicos, desarrollando una actividad incuestionable hasta bien entrado el siglo XVIII. Su procedencia podía ser bien diversa dentro del territorio peninsular e incluso de ultramar, pero el orgullo de su estirpe los englobaría en todo momento

\footnotetext{
$1 \quad$ Universidad de Granada

E-mail: joadiaz@correo.ugr.es
} 
bajo la denominación común de canteros vizcaínos. Ya desde los inicios de esta consideración, se encuadraba dentro de sus relativas lindes a aquellos maestros del arte de la estereotomía que eran oriundos no sólo del Señorío de Vizcaya, sino también del resto de las circunscripciones vascuence, cántabra y navarra ${ }^{2}$.

Todos ellos procedían de un tronco común vizcaíno ramificado en numerosas escuelas de cantería locales, integradas por varones que se hacían herederos de un conocimiento y praxis de la estereotomía, transmitida por generaciones pretéritas. Este bien considerado oficio no revestía ningún secreto para ellos, por lo que su fama se vio consolidada prontamente y sus habilidades altamente solicitadas por todo lo largo y ancho de la geografía hispánica. Así, de las dinastías primigenias surgirían nuevas líneas sucesorias en prácticamente cualquier región, pero el objeto de estudio del presente artículo hará que el interés científico se ocupe solamente de las dimensiones territoriales que suponen las actuales provincias de Granada, Málaga y Córdoba.

Fue en estos tres territorios en los que desarrolló su vida conocida y su actividad el maestro cantero y arquitecto Melchor de Aguirre. Remarcar su importancia como influjo decisivo en las producciones arquitectónicas del último barroco andaluz sería caer en la redundancia, de no ser porque, salvo en casos muy puntuales, el halo de misterio que envuelve a su figura y la desaparición contemporánea de su obra implican que se presente como un gran desconocido dentro del campo de la historiografía del arte actual.

Sobre sus orígenes, a día de hoy sigue sin constatarse vestigio documental alguno que permita arrojar luz y establecer consenso con alguna de las dos teorías que prevalecen por el momento. La primera de ellas y más aceptada emana de los estudios del profesor René Taylor sobre la escuela de cantería cordobesa en el Barroco, quien ubica su nacimiento en San Sebastián hacia $1640^{3}$. Por otra parte, el cronista cordobés José Valverde Madrid, compartiendo una línea de investigación idéntica a la del anterior, apuesta por la "patria chica" y señala la naturalidad de Aguirre en el municipio de Cabra por el año $1630^{4}$.

Sin lugar a dudas, la conclusión de ambos eruditos, de feliz memoria, resulta valiente $y$, en la opción del profesor Taylor, justificada en la asimilación con cierto homónimo y, a un mismo tiempo, homólogo donostiarra de la señalada etapa. Sin embargo, la proliferación por los dominios hispánicos de las familias de canteros vizcaínos aludidas dificulta sobremanera la identificación precisa de una gran mayoría de ellos, de quienes se carece de datos concretos de sus biografías. Sin ir más lejos y manteniendo la atención únicamente en la saga de los Aguirre, entre la segunda mitad del siglo XVI y la primera del XVII, queda documentada la labor de diez canteros que responden al nombre de Pedro de Aguirre, otros seis llamados Miguel de Aguirre y otros tantos con el nombre de Juan, José, Martín, Manuel, Melchor, Domingo, Ignacio, Esteban... Y cada uno de ellos figura asentado y/o trabajando en una ciudad o villa diferente ${ }^{5}$.

2 Cfr. BARRIO LOZA, J.A. y MOYA VALGAÑÓN, J.G. "Los canteros vizcaínos (1500-1800): diccionario biográfico", Kobie, nº11 (1981), pp. 173-174.

3 TAYLOR, R. "Estudios sobre el Barroco andaluz. Construcciones de piedra policromada en Córdoba y Granada", Cuadernos de Cultura, n $^{\circ} 4$ (1958), pp. 33 y ss.

4 VALVERDE MADRID, J. Ensayo socio-histórico de retablos cordobeses del siglo XVIII, Monte de Piedad, Córdoba, 1974, pp. 18-19.

5 BARRIO LOZA, J.A. y MOYA VALGAÑÓN, J.G. Ob. cit., pp. 177-180. 
Por otra parte, la presencia de canteros vizcaínos en las provincias andaluzas señaladas se remonta prácticamente a los años inmediatos a la conquista de Granada. En la Capital Nazarí, para el año 1509 ya existe constancia de la presencia de Cristóbal y Nicolás de Adonza, padre e hijo, trabajando como canteros con Lorenzo Vázquez en las obras de la Capilla Real ${ }^{6}$. Así también, para la primera etapa constructiva de la Catedral, Diego de Siloe cuenta entre la nómina de sus canteros asentadores apellidos de otras familias tan significativas como Álava, Arta, Arteaga, Bolívar, Gaviria, Marquina, Rexil, Vidania y un larguísimo etcétera que conformaba las cuadrillas de vizcaínos traídas por el burgalés hasta Granada ${ }^{7}$. Muchos de ellos quedarían en este territorio para recibir nuevos encargos, como es el caso de Pedro de Asteasu en la Iglesia de San Miguel de la misma urbe ${ }^{8}$, el Maestro Alzaga en el Convento de San Francisco de Baza ${ }^{9}$ o Pedro de Azpeitia en la Iglesia Mayor de Alhama ${ }^{10}$.

Como era de suponer y aunque con una menor intensidad, la ciudad de Córdoba también contó en este periodo con insignes familias de canteros vizcaínos, siendo las más conspicuas las apellidadas Garin, Ibarra y, especialmente, Ochoa ${ }^{11}$. Otro tanto ocurre en Málaga con los Atarren, los Vergara y los Aguirre ${ }^{12}$. De hecho, será en la capital malacitana donde pueda documentarse la presencia más remota de un cantero de la estirpe de los Aguirre en Andalucía. Se trata de Pedro de Aguirre, oriundo de Corella, quien realiza en esta última ciudad numerosos trabajos menores entre 1588 y 1614, como el levantamiento de columnas y pilares, la composición de pesebres, pilas y fuentes, así como la erección de tres portadas civiles, estando afincado en sus últimos años en la calle Trinidad ${ }^{13}$. Poco más se sabe de su vida, de su prole o de su taller, pero queda evidenciado que es el fundador de una sólida estirpe de maestros de cantería que aún pervivía en pleno siglo XVIII, ahora con otro Pedro de Aguirre, asentista en las canteras de Alfayate y Alhama, responsable de la extracción de piedra para las obras de la Catedral de Málaga entre 1753 y $1757^{14}$.

Empero, no es posible establecer relación documental alguna entre el arquitecto Melchor de Aguirre, que es objeto de este estudio, y la saga de canteros fundada por Pedro de Aguirre en la capital malagueña a finales del siglo XVI, aunque su pertenencia a la misma justificaría sobremanera el hecho probado de que los primeros encargos que recibe Melchor en solitario tienen lugar en Málaga como simple cantero. Tal es el caso de los dos púlpitos ejecutados para la catedral en 1674, por encargo del obispo fray Alonso de Santo Tomás ${ }^{15}$; o también de aquellos otros trabajos civiles de que se ocupó hasta el final de sus días, caso de los molinos levantados en la Villa Condal de Teba en $1695^{16}$. En consecuencia y como se analizará en los próximos párrafos, la misteriosa figura de Melchor de Aguirre era bien conocida en los círculos

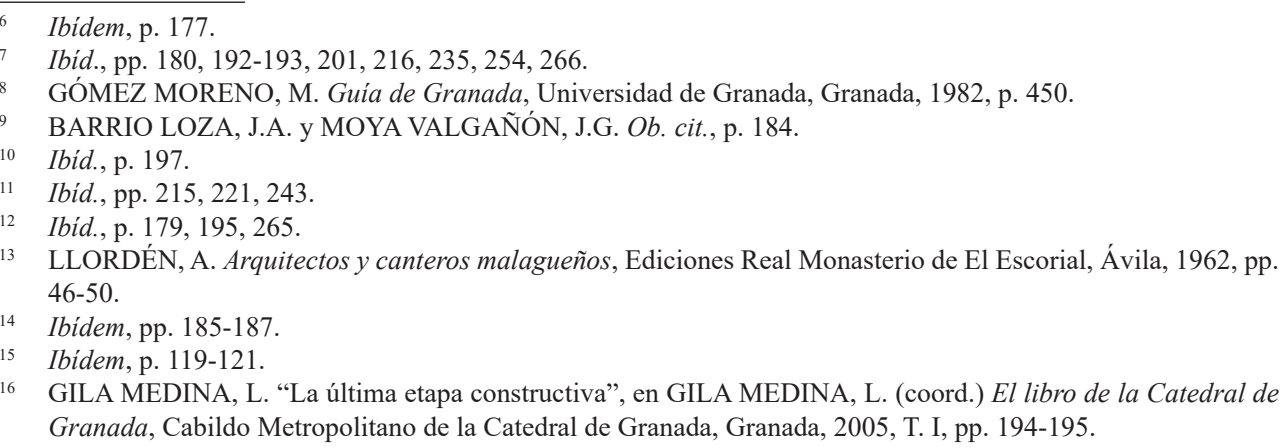


malagueños, puesto que los púlpitos catedralicios no suponen un encargo menudo, lo que mueve a lanzar la hipótesis, nada descabellada, de su pertenencia inicial al taller malacitano de los Aguirre.

Así pues, a continuación, este estudio se ocupará de realizar una reconstrucción de esta desbordante personalidad artística a través de su corpus de retablos y portadas, campo en que fue más prolífico, así como de establecer una primera periodización en la evolución de su carrera como cantero y arquitecto de vocación eclécticamente barroca.

\section{La primera etapa (h. 1640 - 1670): el genio entre tinieblas}

Melchor de Aguirre ha pasado a la posteridad como uno de los mayores artífices en el ámbito de la estereotomía, pero, sin lugar a dudas, era mucho más que eso. Aguirre era un arquitecto auténtico y completo, o como los padres oratorianos de Granada sentenciarían «el mayor arquitecto que este siglo ha conocido, como lo demuestran las excelentes obras que, así en otras partes como en ésta, ejecutó en la Iglesia Cathedral, en Sto. Domingo y en la Merced ${ }^{17}$.

Sin que por el momento pueda aportarse una vinculación directa entre sus primeros años y un taller familiar, se hace innegable, como se verá, que su formación inicial discurrió en un taller de cantería, oficio gracias al cual conseguirá subsistir durante toda su azarosa vida. No obstante, existen una serie de aspectos que hacen de Melchor de Aguirre un cantero diferente, que quiere ir más allá y seguir los pasos de los célebres alarifes eruditos de España y de Italia. Aguirre fue cantero, pero también matemático, astrólogo, escenógrafo y, por encima de todo, un sobresaliente arquitecto. Sus obras evidencian que poseía una formación muy cuidada, la cual lo capacitaba para levantar estructuras agradables al orden y armonía que la divinidad habría depositado en el mundo, en el cosmos y en lo imperceptible; todo ello cargado de un complejo sistema iconográfico en el que lo cristiano y lo pagano se dan la mano sin entrar en conflicto. Por si fuera poco, Aguirre llega a profundizar en un concepto de Arte Barroco que va más allá de la integración de las artes, para abogar por la integración de los estilos.

Para mayor inri, en el campo de lo tectónico, Melchor de Aguirre, como buen cantero, acusa una fuerte preferencia por el rigor del paramento sobre la profusión decorativa, limitada a la geometría recta y cortante de los vanos, y de las tarjas inundadas por exuberantes mascarones vegetales, que se intercalan rítmicamente entre el orden gigante de los elementos tenantes, en los que además se fusionan el dórico y el corintio. En alzado huirá de la curva para consagrar la línea recta, pero en planta gustará de alternar diferentes tipologías de bóvedas y trazas mixtilíneas; el esquema de templo preferido es el jesuítico. Dada la copia literal que acabará realizando de numerosos sellos estilísticos, queda más que evidenciado el modelo a seguir por Melchor de Aguirre. Éste no es otro que la reinterpretación del Barroco italiano realizada por el arquitecto jesuita Francisco Bautista (1594 - 1679) y su "quinto orden", en sus trazas para Madrid y Toledo ${ }^{18}$.

17 Archivo Histórico Provincial de Granada [en adelante: AHPG]. Noticias del Templo de María SS ${ }^{\text {ma. }}$ de los Dolores y Congregón. de S. Phe. Neri de Granada, 1792. Fondo Comisión de Monumentos, Libro 7219, p. 3.

18 HENARES CUÉLLAR, I. "La Catedral: estética y proyección urbana”, en GILA MEDINA, L. (coord.) El libro 
Por tanto, con anterioridad a su primera aparición documentada en Andalucía en 1670, resulta más que claro el hecho de que Melchor de Aguirre, en un momento de su etapa de formación pasó por la Corte y conoció muy de cerca al padre Bautista, a sus creaciones, a sus teorías y a su forma de reinterpretar a Giacomo de la Porta y a los barrocos romanos. Todo ello debió concitarse con tal intensidad, que marcó y definió para siempre a un nuevo Aguirre que no dudaba en manifestar sus inquietudes a la hora de reinterpretar los diseños de otras regiones y de otras épocas, pero a cuyo favor pocas veces jugaron el tiempo y los recursos.

Así también, en el ámbito cortesano fue donde conoció a quien le ofrecería su protección y promoción: don Francisco María Fernández de Córdoba Folch de Cardona y Requesens (1626 - 1688), VIII Duque de Sessa, VII Duque de Soma, VI Duque de Baena, X Conde de Cabra, XI Conde de Palamós, Grande de España, Comendador de la Orden de Calatrava, Virrey de Cataluña entre 1669 y 1673, Presidente del Consejo de Órdenes entre 1677 y 1687, Gentilhombre de Cámara del rey Felipe IV y Caballerizo Mayor de Carlos II $^{19}$. Para las empresas de tan poderoso hombre de estado ejercía de maestro mayor de obras el arquitecto egabrense José Granados de la Barrera ${ }^{20}$, quien introduciría a Aguirre en su etapa definitiva de formación como arquitecto, para inmediatamente después convertirlo en sus ojos y sus manos en su taller de la villa cordobesa de Cabra.

Otro de los puntos clave en la formación de Aguirre era su singularidad «no sólo en la Arquitectura, sino también en la Astrología ${{ }^{21}}^{21}$. Era habitual que el humanismo de los siglos XVI y XVII concediese un lugar principal a la interpretación de los astros $^{22}$, considerada como una ciencia que entraba en contradicción con algunos principios doctrinales del cristianismo, pero que era tolerada por las jerarquías y hasta empleada con frecuencia como recurso de precaución. Por este motivo, no era raro que las figuras del matemático y del arquitecto fuesen parejas a las praxis astrológicas. Se consideraba que la divinidad también manifestaba su favor a través de la posición de los astros, por lo que la realización de una nueva construcción solía estar sujeta a que la posición de aquellos fuese favorable para el acometimiento de tal empresa. Hasta tal punto fueron consideradas estas interpretaciones, que con frecuencia los alarifes van a quedar asociados como expertos conocedores del devenir de los cuerpos celestes. Así, el arquitecto y humanista Fernán Pérez de Oliva, colaborador de las trazas de Juan de Álava, diría de sí mismo hacia 1525:

«En Mathemáticas, todos mis contrarios porfían que sé mucho, así como en Geometría, Cosmographía, Architectura, Prospectiva, que en aquesta Universidad he leído... Unos dicen que soy Gramático, y otros que soy Retórico, y otros que soy Geométra y otros que soy Astrólogo. Y uno dijo en un conciliábulo, que me había hallado otra tacha más, que sabía Architectura ${ }^{23}$.

de la Catedral de Granada, Cabildo Metropolitano de la Catedral de Granada, Granada, 2005, T. I, p. 269.

19 ÁLVAREZ Y BAENA, J.A. Hijos de Madrid, ilustres en santidad, dignidades, armas, ciencias y artes, Oficina de D. Benito Cano, Madrid, 1790, T. II, pp. 207-208.

20 MORENO HURTADO, A. Las calles de Cabra: urbanismo y sanidad durante la Edad Moderna, El Egabrense, Cabra, 2007, p. 572.

21 Archivo Histórico Diocesano Granada [en adelante: A.H.D.G.]: Libro de erección de la Congregación de San Phelipe Neri, h. 1700. Fondo Conventos, libro 7655, s.n.

22 VICENTE GARCÍA, L. M. "El engarce de la astrología en el pensamiento medieval y humanista. El hilo cortado", Revista Española de Filosofia Medieval, no 18 (2011), pp. 193-210.

23 BELTRÁN DE HEREDIA, V. Cartulario de la Universidad de Salamanca (1218-1600), Ediciones Universidad, 
Son estas palabras las que evidencian la normalidad de la práctica de la astrología como una ciencia incuestionable, que era inherente a la estimación de todo humanista que pretendiese construir la Cristiandad del futuro mirándose en la Antigüedad Clásica y evolucionando desde ella. En sus Vidas, Giorgio Vasari diría de Lorenzo della Volpaia ser «buon maestro d'orivoli e quadranti, e bonissimo astrologo, ma sopra tutto eccellentissimo maestro di levar piante $\rangle^{24}$. Ello sin obviar el modo en que el mismo Vasari puso de manifiesto la manera en que Rafael Sanzio, con su archiconocida Escuela de Atenas lo que pretende es representar a los sabios de todos los tiempos «accordano la filosofia e l'astrologia con la teologia» ${ }^{25}$. Y a ello no le pondrá fin la Contrarreforma, sino que en su seno y en pleno siglo XVII se concebirán obras tan principales como el Tratado de astrología, de diferentes formas de levantar figuras, del catedrático de la Universidad de Alcalá de Henares, Diego Pérez de Mesa, quien aplica las lecturas astrológicas sobre la ingeniería, la medicina y ciertos aspectos de la existencia humana, más allá del recurrente campo de la gnomónica ${ }^{26}$. No extraña, por tanto, que Melchor de Aguirre se viese afectado y condicionado por este tipo de cuestiones indirectas a la hora de dar trazas, las cuales, como se verá, llegarán a incorporar signos y morfologías de una clara lectura astrológica.

\section{La segunda etapa (1670 - 1679): el cantero egabrense}

José Granados de la Barrera recibió el nombramiento de Maestro Mayor Honorífico de las obras de la Catedral de Granada en el año $1668^{27}$, acontecimiento que en la trayectoria de Melchor de Aguirre se traduciría en el traslado desde la villa de Cabra, donde probablemente ya se encontraba avecindado, hasta la ciudad de Granada en 1670. Allí comenzaría a trabajar como cantero asentador a las órdenes del maestro Juan del Páramo en las obras de la torre y fachada de la sede metropolitana granadina, con un salario de 45 reales por cinco días trabajados ${ }^{28}$. Este hecho supondría la introducción de Aguirre en el próspero ambiente granadino, a la par que, por otro lado, consolidaba su maestría en el medio egabrense, donde para el año 1676 ya figura como nuevo Maestro Mayor de las obras del Duque de Sessa, en sucesión de Granados, y avecindado en dicha villa, en una casa de la calle de las Parras ${ }^{29}$. En esta vivienda funcionaría ya también su propio taller, como nuevo núcleo aglutinador de canteros vizcaínos, entre los que destacaba un joven Juan de Ochoa ${ }^{30}$, de la citada a priori estirpe cordobesa de los Ochoa.

Desde dos años antes, en 1674, queda documentada la presencia de Melchor de Aguirre como maestro de cantería que dirige la etapa final del levantamiento del retablo mayor de la Iglesia de Ntra. Sra. de la Asunción y Ángeles de Cabra, bajo la

Salamanca, 1971, T. III., p. 259.

24 VASARI, G. Le vite de' più eccellenti pittori, scultori e architetti, Pazzini Carli e compagno, Siena, 1792 , T. VIII, p. 13.

$25 \quad$ Ibidem, T. V, p. 257.

26 Biblioteca Nacional de España [en adelante: BNM]: PÉREZ DE MESA, D. Tratado de astrología, de diferentes formas de levantar figuras, manuscrito, s. XVII. Sig. Mss/5995.

27 GILA MEDINA, L. Ob. cit., T. I, p. 194.

28 Ibidem, pp. 194-195.

MORENO HURTADO, A. Ob. cit., p. 501.

$30 \quad$ Ibídem, p. 450. 
traza de Granados ${ }^{31}$. En este diseño es notable la influencia de los planteamientos de Alonso Cano para retablos como el de la iglesia madrileña de San Andrés, de gran simplicidad y una absoluta depuración formal, cuyo barroquismo se refugia en el dinamismo que ofrecen los juegos de volúmenes y de la policromía, que a posteriori heredará Aguirre.

De este modo, el retablo queda inserto dentro del marco previo de un arco triunfal, en este caso perialtado para destacar la parte central de la cabecera practicada en la antigua mezquita. La estructura se desarrolla en lo fundamental: sotabanco, banco, un cuerpo central dividido en tres calles y un ático semicircular también tripartito, separado todo ello por molduraciones escalonadas. La calle central sobresale considerablemente al avanzar en planta sobre las otras dos mucho más estrechas, de manera que tan sólo aquella es la que contiene carga catequética, al dedicarse el cuerpo central al camarín de la Virgen de la Asunción y Ángeles, y la del ático a una pintura central desaparecida, cuyo espacio hoy lo ocupa un crucificado. Mientras que, en el banco, el sagrario queda custodiado por un friso de placas recortadas en mármol rojo, este mismo material sirve para dar corporeidad a las molduras, ábacos, fondo del ático y las dos columnas que enmarcan el camarín. En contraste, el nicho central del ático queda custodiado por dos pilastras estriadas en mármol negro, materia que comparte con los fondos de las calles laterales de todo el retablo, las placas recortadas con que se ornamenta el interior de ábacos y podios, y las dos columnas que se anteponen en las calles laterales del piso central. Todos los capiteles, basas y claves quedan sobredorados de manera que se acusan los contrastes cromáticos del orden compuesto. De esta forma, las calles laterales son un mero espacio para el desarrollo básico de una ornamentación tectónica, que en el ático se materializa a través de dos flameros sobre podios. La placa recortada se convierte, siguiendo a Cano, en el elemento decorativo fundamental, que se antepone a los ábacos y podios, llegando incluso a absorber el espacio central del alfiz, posibilitando nuevas formas geométricas en las enjutas.

No es posible obviar el hecho, ya descrito, de la ejecución del primer encargo a que responde Melchor de Aguirre en solitario y declarando hallarse avecindado en Cabra, relativo a la factura en 1674 de las cajas de los púlpitos de la Catedral de Málaga. Su diseño, dado por el dominico fray Juan Bautista, se hace bastante parco, en planta hexagonal y con una ornamentación limitada a la heráldica episcopal en cada una de sus caras. No obstante, la ejecución de Aguirre resulta detallada y minuciosa en lo que se refiere a la recreación de los blasones, ya que el resto de la estructura es bastante simplificada, sin que sea reconocible signo alguno de su autoría, más allá del uso de la placa recortada como marco de la heráldica y sello preferido del Aguirre cantero.

Este segundo periodo reconocible en la biografía de Aguirre, supone para el alarife la consolidación de sus conocimientos y destrezas en el campo de la arquitectura, inicialmente a la sombra de un José Granados de la Barrera que no tardará en conducirlo de la mano hacia la obtención de su propia maestría. Asimismo, le haría entrar en contacto con el legado del genial Alonso Cano, conocimiento que acabará aglutinando con las trazas de Francisco Bautista en sus futuros diseños, más allá del ámbito del retablo canesco que también pudo captar sus intereses durante sus años de estancia en la Corte. Además, como cantero de cuna, Aguirre verá brindada la

31 RAYA RAYA, M.J. El retablo barroco cordobés, CajaSur, Córdoba, 1987, pp. 53 y ss. 
oportunidad de dirigir los trabajos de la piedra en una de las canteras más ricas y codiciadas del momento, fruto de la exclusividad cromática de la rúbea veta marmórea en Cabra, debiendo atender sin duda a la realización de diversos encargos de menor envergadura, tal y como lo pone de relieve la existencia y puesta en marcha de su propio taller.

\section{La tercera etapa (1679 - 1685): el maestro de canterías}

El año 1679 marcaría el punto de inflexión en la carrera, hasta el momento aparentemente monótona de Melchor de Aguirre, cuando el obispo de Córdoba, fray Alfonso de Salizanes y Medina, lo contrata para los trabajos de su capilla funeraria, dedicada a la Inmaculada Concepción y al Santísimo Sacramento, en el extremo de la Epístola de la catedral cordobesa ${ }^{32}$. Con él, participarían Pedro de Mena y Juan de Alfaro, para atender a los encargos de talla en madera y pintura, respectivamente. Los relieves pétreos y los trabajos de cantería de la portada y el retablo correrían a cargo de Aguirre y su taller, para componer una de las intervenciones más sobresalientes que se llevarían a cabo durante el siglo XVII sobre la fábrica de la antigua Mezquita Mayor. Por vez primera, es posible asistir a la creación de un trabajo salido del ingenio de Melchor de Aguirre, poniéndose así de manifiesto los niveles de que ya gozaba su prestigio como maestro de cantería y escenógrafo del mármol. Tanto es así, que su taller atraería a nuevas personalidades, tales como el egabrense Fernando Muñoz Romero $^{33}$ o el asturiano Toribio de Bada, quien tan sólo cinco años antes trabajaba en la erección de las Casas Consistoriales de Avilés ${ }^{34}$.

La Capilla Salizanes se reviste en su mayor parte con piedra de las canteras de Cabra, generando una intensa impronta rojiza, que contrasta con la piedra cipia de Luque y el mármol negro que conforman los elementos decorativos. De una parte, cabe distinguir la portada de la capilla, mucho más simple, pero ya con un sello netamente aguirreano e inevitablemente afectado por las estructuras canescas. El acceso se lleva a cabo a través de un gran arco de medio punto, cuyos elementos tectónicos se han abandonado a la abstracción geométrica. Las dos pilastras laterales, con todos sus elementos, se han fundido del todo con el alfiz, predominando en ello el rigor de la línea recta. Capitel, basa y podio simplemente se insinúan con formas rectilíneas rotas por la acanaladura que integra a todas estas piezas en el espacio de las enjutas. La moldura escalonada perfila la totalidad de cada uno de los elementos, contribuyendo al juego de volúmenes y de sombras, y desdoblándose en los ángulos superiores, tal y como Aguirre repetirá hasta la saciedad en la mayor parte de sus creaciones. Así sucede también en el ático de esta portada, donde un voluminoso marco cuadrangular contiene el nicho avenerado con la efigie de la Inmaculada Concepción coronada por los ángeles de las enjutas, todo ello en piedra blanca.

Precisamente, son los tonos albos de la piedra cipia de Luque los que se reservan para aquellos elementos que suponen la irrupción de la vida en medio del páramo

32 ROMERO TORRES, J.L. "Pedro de Mena, Pedro Roldán y el concurso artístico de fray Alonso de Salizanes, Obispo de Córdoba", Laboratorio de Arte, nº 24 (2012), pp. 259-263.

33 CORTE Y RUANO, M. "Curiosidades naturales de España. La Sima de Cabra”, Semanario Pintoresco Español, Serie II, T. I (6 de enero de 1859), pp. 25-27.

34 MADRID ÁlVAREZ, V. "El arquitecto Juan de Estrada y la persistencia del Clasicismo en Asturias", Boletín del Seminario de Estudios de Arte y Arqueología, no 79 (2013), pp. 93-116. 


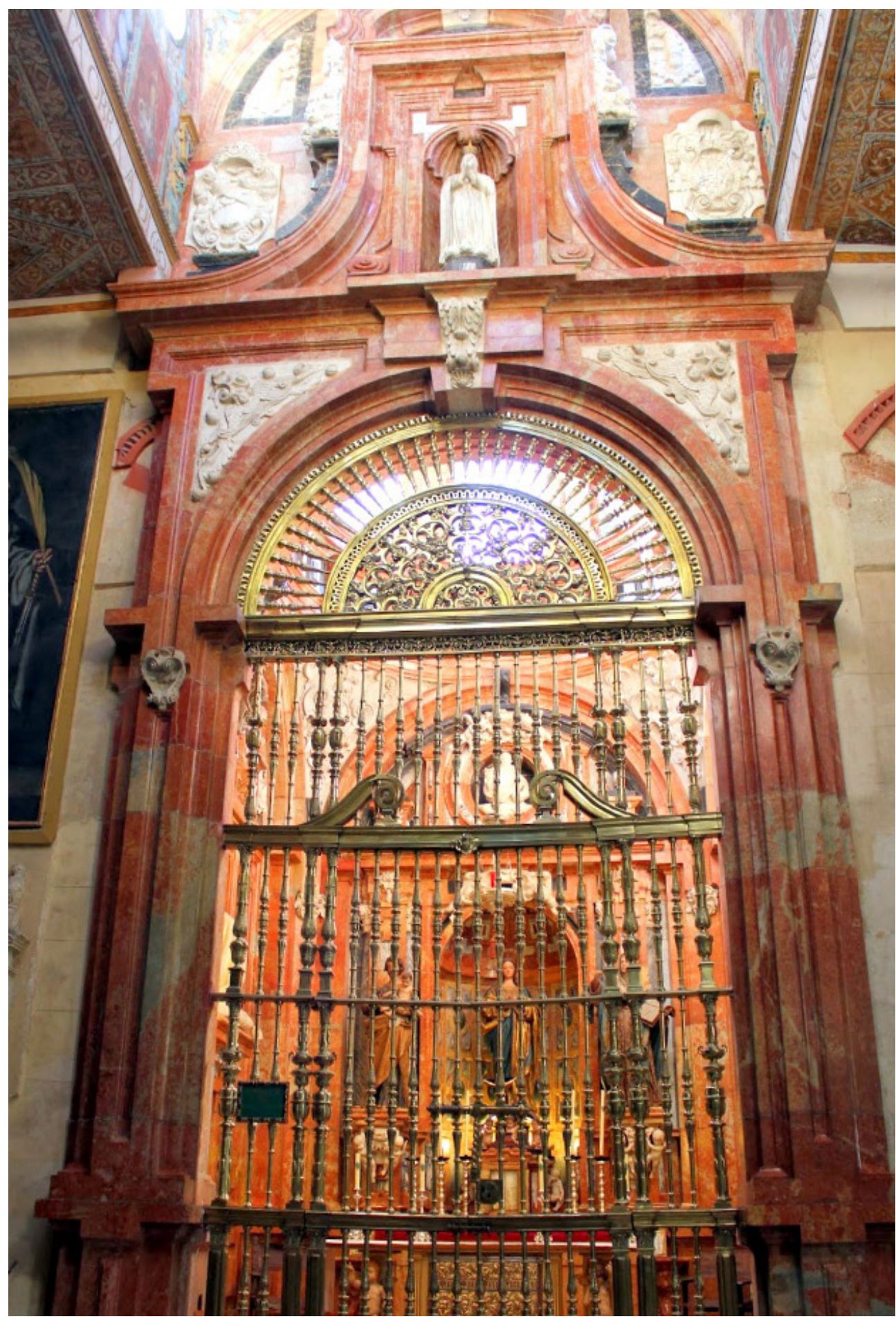

Figura 1. Melchor de Aguirre, Portada de la Capilla Salizanes, Catedral de Córdoba, 16791680. Autor: José Antonio Díaz Gómez [en adelante: JADG] 
tectónico y geométrico: las parejas de ángeles juguetean con motivos vegetales en las enjutas; golpes de exuberante hojarasca recrean mascarones y acantos con que se coronan fingidos fustes y los definidos acantos en las claves de los arcos de ambos cuerpos estructurales; la heráldica y las enjutas vegetales superiores también comparten esta nobleza, así como la profusa hojarasca que emana de las molduras de piedra negra que, a la manera de rígidas cornucopias, se adhieren a los perfiles curvos del cuerpo central del ático.

Al interior, en este juego en que lo tectónico consigue imponerse a lo ornamental, lo geométrico a lo voluptuoso, la placa recortada continúa siendo conducida a sus máximas posibilidades. En este espacio, el mármol blanco se reserva para representar el plano espiritual, inundado por la claridad de la vida representada en las efigies orantes de los difuntos, nuevamente en los ángeles tenantes de voluminosa hojarasca, en la nobleza de la heráldica familiar y de los blasones que contienen las letanías lauretanas y, en el retablo, también en la efigie bendecidora del Padre Eterno realizada en bulto.

El retablo que preside esta capilla queda perfectamente integrado en el conjunto decorativo, sin que por ello medre la distinción canesca del marco de medio punto moldurado para dignificar el espacio principal. Desaparece el banco en la estructura de este retablo, ya que aquel queda roto en toda su amplitud central por la exedra que parece querer imitar la estructura de los manifestadores de colmena. Se trata de una exedra que tiene una finalidad absolutamente iconográfica, dado que, en lugar de aislar el sagrario del resto del conjunto, lo integra para generar el mensaje inmaculista en línea descendente: desde la altura del ático, Dios Padre se asoma para enviar su Espíritu a María Inmaculada, a través de la cual él mismo se hará carne eucarística. De este modo, el sagrario, manteniendo sus proporciones habituales, adquiere la morfología de un tabernáculo marmóreo custodiado por cuatro ángeles, sobre el que se sostiene la talla de la Inmaculada de Pedro de Mena. El interior de la exedra se llena con cuarterones y semiesferas en piedra roja, verde y gris, generando la señalada sensación de ser un gran manifestador petrificado.

Por su parte, las calles laterales se reservan a las tallas de San José y Santa Ana del mismo escultor, que se sostienen sobre repisas marmóreas, adosadas a pilastras recorridas por placas recortadas en mármol rojo de Cabra y blanco de Génova, a las que, a su vez, se adosan en los ángulos cuartos de columna de un nuevo orden, con blanco capitel corintio y gris fuste entorchado en su extremo inferior y con dientes de sierra en lo restante. Así también, el ático se soluciona con una gran estructura semicircular que avanza sobre el perfil de sus calles laterales, completadas con bolas herrerianas policromadas en damero sobre podios contenedores de hojarasca. El interesante frontón, encierra un potente marco cuadrangular desdoblado en las esquinas superiores, que a su vez contiene el óculo desde el que se asoma la efigie del Padre Eterno: el cuadrado encierra al círculo como signo del cosmos dominado por el Creador. En las enjutas que se generan por todo el retablo no se integran las placas recortadas ni la hojarasca, sino que se superponen los jaspes con forma piramidal.

Nada en esta gran Capilla de la Concepción y del Santísimo es casual. Se combinan la recta y la curva, lo inerte y lo fértil, con la bella policromía de los mármoles. La piedra roja de Cabra es el plano terreno sobre el que se manifiesta la vida celestial e inagotable, plasmada en la pureza de la piedra blanca, unida al mundo por una espiritualidad ascendente y manchada por el pecado representada en el mármol gris, reservando la piedra negra para aquello que circunda la Creación pero queda fuera 


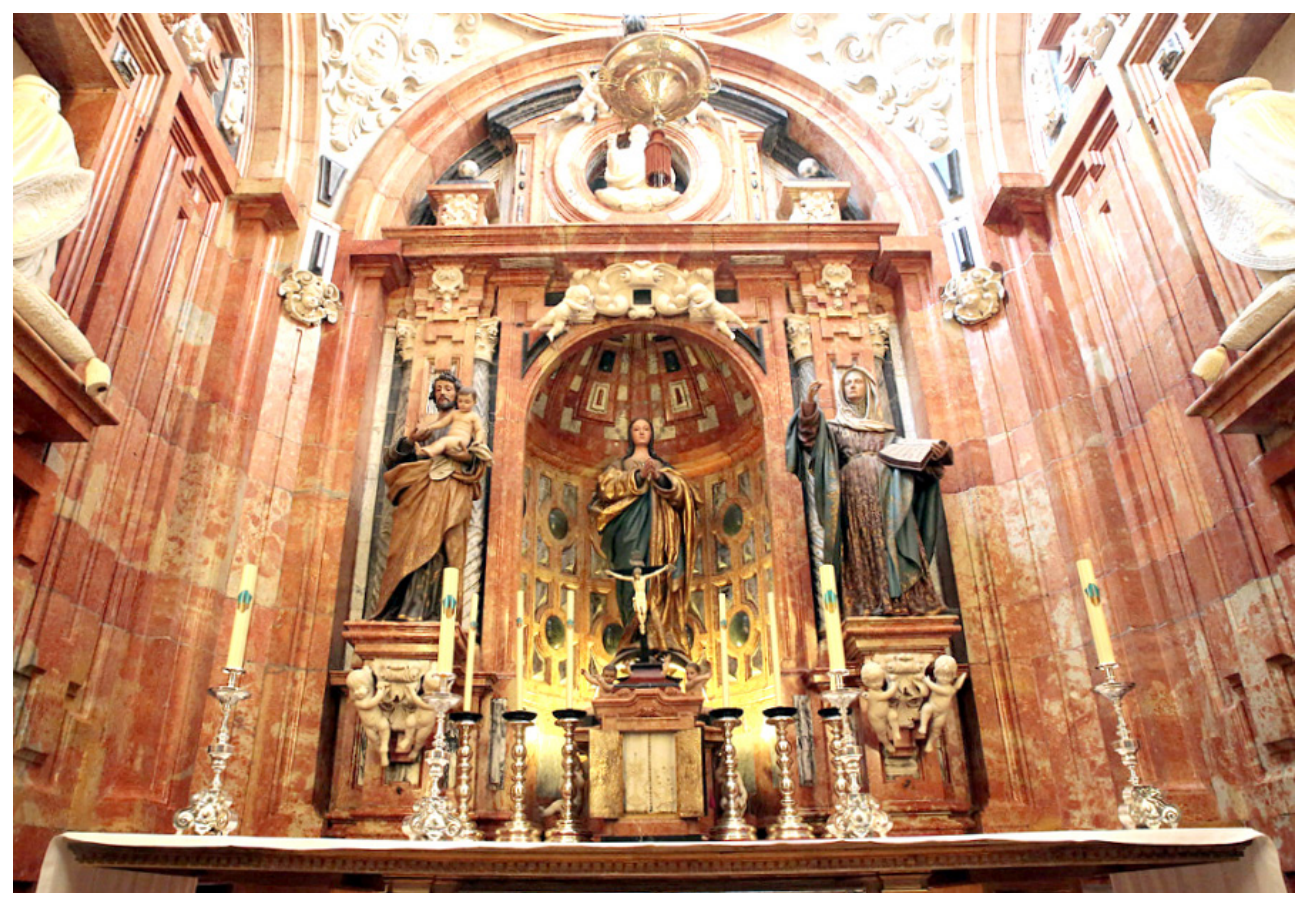

Figura 2. Melchor de Aguirre, Retablo de la Capilla Salizanes, Catedral de Córdoba, 16801681. Autor: JADG.

de ella, es decir, el inframundo. Dos personajes humanos y pecadores, José y Ana, son el instrumento de que Dios se vale para que en medio del incierto mundo irrumpa con toda fuerza María libre de toda mancha, y cumpla su misión de engendrar al Salvador. Es esta la lectura iconográfica que puede extraerse del caprichoso encargo que el obispo Salizanes realiza a través del superintendente Juan Bautista Montesinos, quien especifica en el contrato de la obra la dignidad del material con que cada elemento debe estar caracterizado, cuyo corte y extracción estuvieron dirigidos por Aguirre:

«los colores blanco y negro de la traza, de jaspe; el color amarillo, de piedra cipia de Luque de la mejor; los tablones que van entallados de perfil de jaspe de Cabra; las sombras que causaren los cuatro cuartos de columnas por perfil han de ser de piedra negra y perpendicularmente en las sombras que causa el segundo cuerpo; los cuerpos de los diez niños han de ser de mármol blanco de Génova que tengan pulimento; y los santos han de ser de madera, estofados y dorados. El jaspe de Cabra que se gaste ha de ser de cabeza de lo mejor que se hallare, procurando que se imiten unos a otros con los matices nativos» ${ }^{35}$.

Aunque la Capilla Salizanes de la Catedral de Córdoba no se consideró concluida hasta que Cristóbal de León instaló la reja a finales de noviembre de 1682 , lo cierto es que los trabajos de cantería de que era responsable Melchor de Aguirre

35 ROMERO TORRES, J.L. "Pedro de Mena, Pedro Roldán y el concurso artístico de fray Alonso de Salizanes, Obispo de Córdoba", Laboratorio de Arte, n 24 (2012), p. 260. 
finalizaron en corto plazo de tiempo. La portada de acceso se levantó entre el 14 de septiembre 1679 y tras su término, el 4 de octubre de 1680 recibió el encargo de la realización del retablo, con el compromiso de volver a ejecutar el encargo en el plazo de un año, lo cual cumplió, por lo que recibió una remuneración de 55.000 reales en cuatro pagas trimestrales desde la firma del contrato ${ }^{36}$.

Pocos días tras asumir la hechura del retablo, se dejaban sentir en la provincia de Córdoba las nefastas consecuencias del terremoto del 9 de octubre de 1680, con epicentro en la ciudad de Málaga ${ }^{37}$. Como resultado, de un lado, Aguirre se hará cargo en 1681 de la reconstrucción de la torre de la Iglesia de San Francisco Solano de Montilla ${ }^{38}$, con esquemas volumétricos que se miran en la torre de la Catedral de Granada. Por otra parte, la Iglesia de Ntra. Sra. de la Asunción y Ángeles de Cabra se vio afectada por los temblores, por lo que Aguirre acometió la recomposición tanto del retablo mayor, que había culminado unos años antes, como de los retablos de las dos capillas laterales de la cabecera, dedicados a Santiago Apóstol y a santa Catalina ${ }^{39}$. Será en estos dos últimos, donde Aguirre respetará los elementos preexistentes para potenciar la profusión decorativa. De este modo, introduce nuevamente un perfil mixtilíneo en planta, nichos avenerados, voluminosos marcos arquitectónicos $\mathrm{y}$, por vez primera en su trayectoria, plantea la presencia de columnas salomónicas pareadas en las calles laterales, aunque manteniendo el juego polícromo de los mármoles y dorados que idea Granados para el retablo mayor.

\section{La etapa final (1685 - 1697): el maestro de maestros}

El de 1685 será un año clave en el desarrollo vital y profesional de la vida de Melchor de Aguirre a causa del fallecimiento de su último maestro, José Granados de la Barrera $^{40}$. No obstante y como se viene remarcando, para esta fecha Aguirre ya era todo un reputado maestro de cantería, cuya actividad le posibilitaba llevar una vida acomodada. De hecho, a la muerte de Granados, será él quien se haga cargo de continuar con los proyectos que su preceptor había dejado inconclusos, especialmente dentro de la evolución de las obras de la Catedral de Granada. Por su cuenta y riesgo, Aguirre seguía atendiendo encargos en las provincias de Granada y Córdoba, por lo que el Cabildo Catedralicio, para asegurarse de su retorno, le impondrá la prestación de algunos de sus bienes a modo de aval ${ }^{41}$. De esta manera, queda constancia sobre cómo Aguirre emplea para este fin algunas posesiones realizadas en metales preciosos, así como un olivar y dos casas que tenía en Cabra. Efectivamente, además de la casa aludida a priori en la calle de las Parras, donde igualmente se localizaba su taller, Melchor de Aguirre ya contaba con la propiedad de una casa solariega en la misma villa, ubicada en la calle de los Naranjos (actual de Pepita Jiménez), frente a la Ermita de Santa Ana ${ }^{42}$.

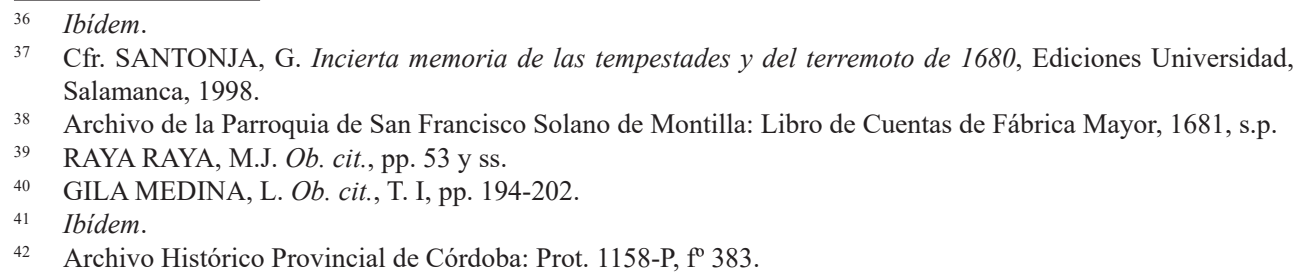




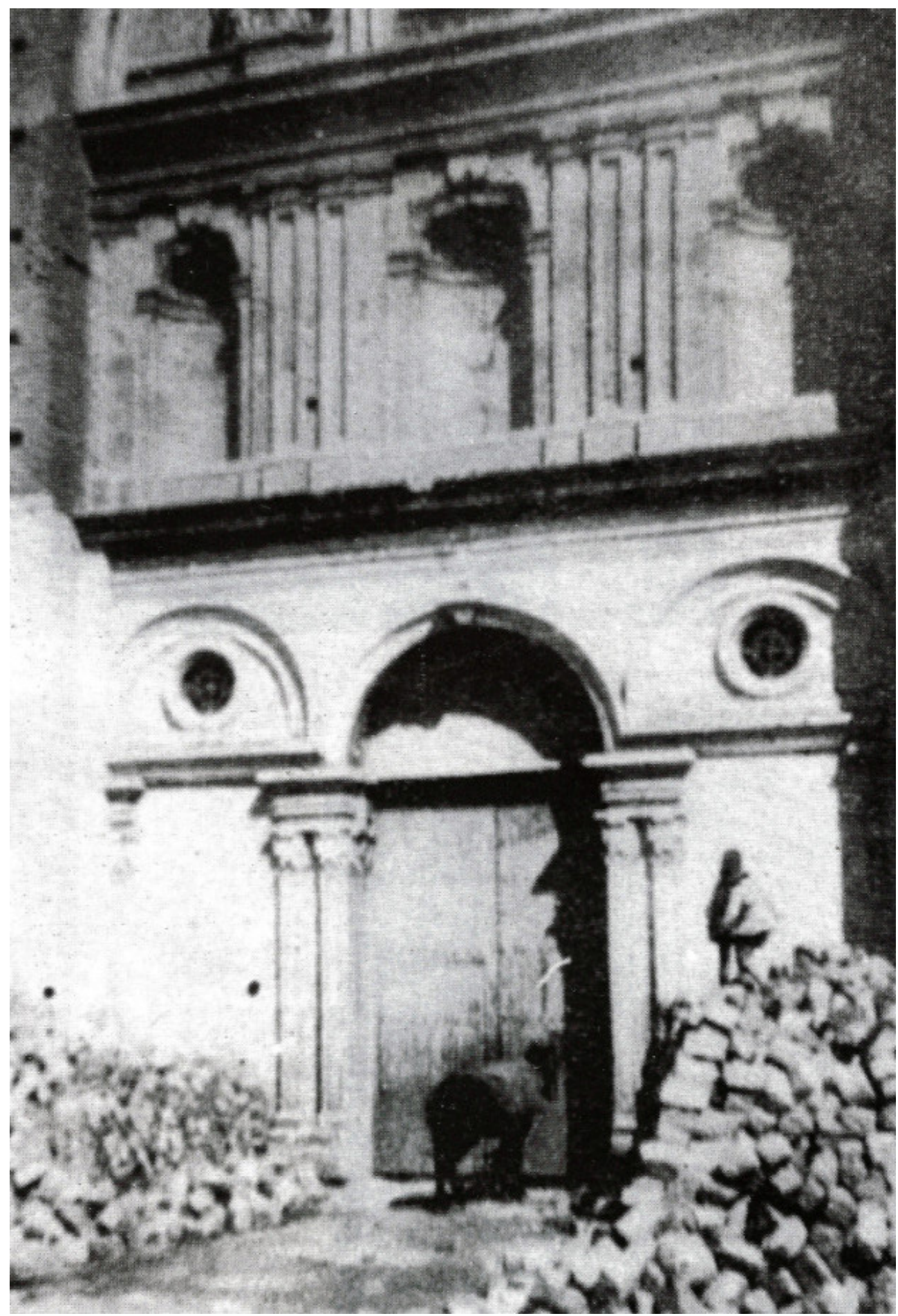

Figura 3. Baltasar de la Pasión y Melchor de Aguirre, Fachada de la Iglesia de Belén, Granada, 1685 - 1724. Autor: JADG. 
Otro proyecto relevante del que parece haberse hecho cargo, desde el deceso de Granados hasta su conclusión en 1699, es la Iglesia del Corpus Christi de las agustinas recoletas de Granada, donde los trabajos debían de encontrarse lo suficientemente avanzados y el diseño original del maestro tan consolidado, que no resulta perceptible la introducción de modificaciones que parezcan llevar la firma de Aguirre, sobre un proyecto inspirado en las trazas primitivas que Alonso Cano ofreciese para el Convento del Santo Ángel Custodio de la misma ciudad ${ }^{43}$.

Con todo, sus principales y mejores clientes serían las órdenes religiosas. En ese mismo año de 1685, la Merced Descalza confiaba en su fama como maestro de cantería para dirigir la edificación de su iglesia conventual en Granada, acogida bajo la advocación de Ntra. Sra. de Belén, de la que tan sólo subsisten algunos testimonios gráficos. Sin embargo, las trazas serían dadas por un arquitecto procedente de las mismas filas de la orden mercedaria, fray Baltasar de la Pasión ${ }^{44}$, el cual, lejos de proporcionar para esta fundación un diseño novedoso, opta por imitar los planteamientos legados en 1612 por Gonzalo Yáñez para la congregación en la Iglesia de Belén de la ciudad de Antequera ${ }^{45}$, con una estructura tripartita bien definida y aséptica, por la cual se aplica un uso racionalista en la modulación de la portada, reservando el primer cuerpo a una triple arquería de acceso, el segundo para las hornacinas y el tercero para el vano de iluminación y la heráldica, rematando todo el conjunto un frontón triangular.

No obstante, en el caso granadino se aprecian algunas distinciones que permiten reconocer la mano de Melchor de Aguirre. En primer lugar, mientras que Yáñez emplea la cantería y el ladrillo en función de las necesidades tectónicas, Aguirre, como siempre hará, dignificará la totalidad del espacio de la portada, como elemento iconográfico y simbólico de relevancia, con el uso de piedra franca en toda ella. Así pues, el conjunto de los tres cuerpos de la portada queda inserto dentro de un gran arco triunfal perfilado por una molduración escalonada, al modo en que Alonso Cano decidió embellecer tectónicamente los diferentes tramos de la torre de la $\mathrm{Ca}$ tedral de Granada. Además, siguiendo la línea de Cano y Granados, Aguirre acusa la diferenciación de los cuerpos mediante unas pronunciadas molduras, que en este caso se hacen dobles. Como pincelada de su formación con Francisco Bautista en la Corte, elimina la curva en la medida de lo posible, sustituyendo el óculo del frontón por un ventanuco rectangular, haciendo cuadrangulares los tres nichos avenerados del cuerpo central y, en la triple arcada de acceso, introduce un dintel en la luz de los arcos laterales; así también, a los extremos del frontón añade dos flameros. Finalmente, para enmarcar el conjunto de la portada, se vale del orden gigante para las dos pilastras que cumplen este cometido y, en los pilares sobre los que se apoya el arco central de acceso, adosa delgadas semicolumnas con un cierto aire medievalizante.

En lo que se refiere a la portada de la entrada auxiliar del templo y dado lo secundario y poco visible del acceso, éste se resuelvía con un sencillo arco de medio punto, sobre el que descansaba una prominente moldura escalonada, a su vez susten-

43 TAYLOR, R. "El arquitecto José Granados de la Barrera", Cuadernos de Arte de la Universidad de Granada, no 22 (1975), pp. 5-14.

44 BERMÚdEZ PAREJA, J. “Convento de Belén”, Boletín de la Universidad de Granada, n 32 (1935), pp. 6064.

45 LEÓN VEGAS, M. "Negro sobre blanco: la Antequera moderna en sus fuentes bibliográficas", Baetica, $\mathrm{n}^{\circ}$ 33 (2011), pp. 299-315. GÓMEZ GARCÍA, M.C. y MARTÍN VERGARA, J.M. "Notas para el estudio del monacato en Málaga y su provincia", Isla de Arriarán, no 25 (2005), pp. 95-111. 
tante de una pequeña hornacina que constituye una portada en miniatura apoyada en el orden toscano y coronada por un acusado frontón triangular. Lamentablemente, de ambas construcciones aguirreanas, a las que probablemente también habría que sumar el camarín del templo, no queda más que el recuerdo nostálgico, dado que, tras ser empleado como prisión pública, se ordenó su demolición en 1933 para la construcción de un colegio en su lugar ${ }^{46}$.

Al año siguiente, en 1686, Aguirre saldría triunfante del concurso para lo que acabaría por convertirse en el mayor de sus proyectos, donde por vez primera pudo desarrollarse plenamente no sólo como maestro cantero, sino también como arquitecto. Se trata de la Iglesia de Ntra. Sra. de los Dolores, trazada para la Congregación del Oratorio de San Felipe Neri de Granada, cuyos integrantes ofrecían este interesante testimonio:

«la [planta] que hoy tiene y se ha seguido, la ofreció el $\mathrm{M}^{\circ} \mathrm{D}$. Melchor de Aguirre, la que entre todas agradó más, aumentando el agrado la oferta del $\mathrm{M}^{\mathrm{o}}$, quien [...] quiso servir de balde y sin ningún estipendio esta obra, esperándolo de Dios, lo que ejecutó hasta morir con imponderable asistencia y solo» ${ }^{47}$.

Sin embargo, pese a ser la más eminente obra de Aguirre, jamás la vería finalizada, ya que la fachada principal no sería culminada hasta 1699, con la portada lateral no ocurriría lo propio hasta 1717 aproximadamente y, finalmente, la capilla mayor sería consagrada en 1725, habiendo ocurrido la muerte de Aguirre en $1697^{48}$.

Melchor de Aguirre se enfrentaba por vez primera en solitario al levantamiento de un conjunto arquitectónico. La circunstancia descrita por los oratorianos parece hablar de la frustración de un arquitecto que no conseguía librarse de las funciones acarreadas por su origen vizcaíno y, pese a tratarse su nuevo cliente de una de las congregaciones más influyentes de la Granada barroca, se ofrece a dirigir la construcción del templo sin ayuda y sin remuneración. Esta situación no implica que Aguirre ya no se moviese de Granada ni respondiese a más encargos que posibilitasen su sustento, aunque sí llevó a cabo una mayor implicación en estos trabajos de manera autosuficiente, hasta el punto de que en los siguientes años el maestro cantero ya será, ante todo, el maestro arquitecto.

Por su parte, el templo de los oratorianos será el único que ponga de manifiesto en su totalidad la identidad artística y, por qué no, personal de Melchor de Aguirre. En lo que al interés de este artículo respecta, el retablo mayor, cuyos restos se conservan mínimamente bajo el actual del Santuario del Perpetuo Socorro, seguía el esquema canesco que el autor ya había considerado para la cordobesa Capilla Salizanes. En este caso, se labra en la misma piedra franca del paramento del testero, a posteriori policromada fingiendo jaspes con el discurso cromático ya conocido, y encajada como un puzle. Sobre el espacio del banco, se desplegaba un grandilocuente cuerpo central separado en tres calles, duplicando en anchura la central a las dos laterales ${ }^{49}$.

46 BARRIOS ROZÚA, J.M. Reforma urbana y destrucción del patrimonio histórico en Granada, Universidad de Granada, Granada, 1998, p. 407.

47 A.H.P.G.: Noticias del Templo de María SS ${ }^{\text {ma. }}$ de los Dolores y Congregón. de S. Phe. Neri de Granada, 1792. Fondo Comisión de Monumentos, Libro 7219, p. 3.

48 GILA MEDINA, L. Ob. cit., T. I, pp. 194-202.

49 AHPG: Expediente de inventario de S. Felipe Neri, 1837-1838, leg. 2432-48. Archivo de los Padres Redentoristas de Granada [en adelante: APRG]: Libro de Crónicas, T. II, p. 339. 
La ornamentación es fundamentalmente tectónica y hasta más racional que en el caso cordobés expuesto, ya que el espacio de las calles se enmarca con cuatro sencillas columnas de capitel corintio y fuste liso en las dos interiores, mientras que para las exteriores es estriado. Las tarjas y las placas recortadas constituyen el elemento básico y casi el único de la decoración, exceptuando la puntual irrupción de la hojarasca en algunos frisos y en las repisas laterales sobre las que se ubicaban las efigies en madera policromada de Santiago Apóstol y San Francisco Javier, protectores de la fábrica del templo ${ }^{50}$. Asimismo, el espacio central queda reservado para el tabernáculo de mármoles, sobre el cual se abre el imponente arco del camarín de la Virgen de los Dolores, tallada por José de Mora en $1671^{51}$. Sobre este último elemento, un gran friso moldurado queda centrado por la talla de Cristo Crucificado, diferenciando el primer piso del siguiente y último, en el cual, nuevamente, la placa recortada es reconducida en sus máximas posibilidades como elemento modulador y ornamental, en un juego que la hace encajar de manera imposible y que a un mismo tiempo resulta racional. A los lados, dos flameros sobre podios. Al centro, un gran óculo reservado a la efigie bendecidora del Padre Eterno. Ni qué decir tiene que la totalidad del conjunto queda inserta en un gran arco de triunfo, de manera que retablo y paramento permanecen visualmente integrados como cosa única e inseparable.

Así también, la portada principal del templo se encuentra drásticamente mutilada tras los expolios desamortizadores. Como la totalidad del edificio, está levantada con gruesos sillares de piedra franca de las canteras de Santa Pudia. Su constitución resulta novedosa dentro de la ciudad de Granada, porque se aleja del concepto de simple portada para recuperar los planteamientos de monumental fachada telón de Francisco Bautista, que desarrollará en su plenitud el Barroco tardío del siglo XVIII. Se trata de una imponente fachada, directamente inspirada en los alzados barrocos de la Catedral granadina, donde el riguroso muro predomina sobre los tímidos vanos y son, de nuevo, los elementos tectónicos los que sirven para modular los espacios y crear un interesante juego dinámico de sombras y perfiles mixtilíneos.

De este modo, la compartimentación modular es ya conocida. La fachada se divide en tres calles, donde, en esta ocasión, la central cuadriplica a las dos estrechas laterales. Sendas tres se encuentran distinguidas por pilastras de orden gigante, lisas en el cuerpo inferior y estriadas en el superior. Así también, se aprecia una clara distinción entre la misión iconográfica que ha de cumplir cada uno de los dos cuerpos. El inferior es el plano terreno, donde la vida es fútil; por ello la decoración del paramento es exigua y, entre los vanos rectangulares de las calles laterales el adorno se limita a una doble placa recortada. No obstante, el tramo central de este primer cuerpo, originalmente se revestía con la nobleza del mármol gris de Sierra Elvira, creando un espacio porticado, ya no a la manera de Granados en el Corpus Christi o de fray Baltasar en la Iglesia de Belén, sino del Padre Bautista en la Colegiata de San Isidro de Madrid o en la Iglesia de San Ildefonso de Toledo. Así, cuatro colosales semicolumnas de orden compuesto generaban un triple espacio de acceso, de amplio medio punto el central y adintelados los laterales, todo ello circundado por una mínima pero imponente ornamentación a base de hornacinas cuadrangulares y tarjas

50 AHPG: Inventarios del edificio y efectos del Convento de S. Felipe Neri, congregación de Clérigos seculares de esta Ciudad, 1837, leg. 2432-28

51 CRUZ CABRERA, J.P. "La imagen religiosa como estrategia fundacional: la Virgen de los Dolores de José de Mora (vulgo Soledad de Santa Ana) y el oratorio de San Felipe Neri de Granada", Cuadernos de Arte de la Universidad de Granada, nº 41 (2010), pp. 131-147. 


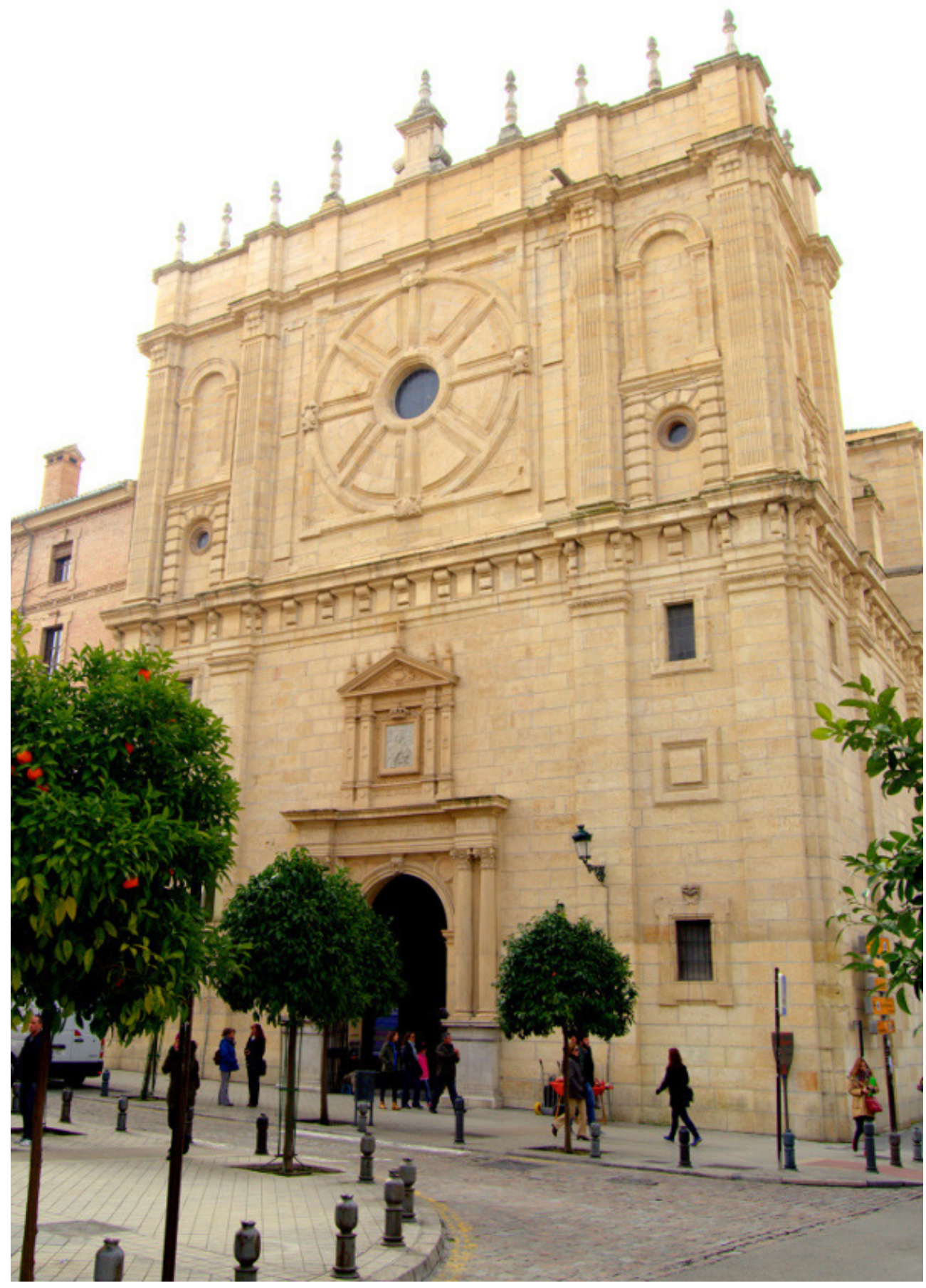

Figura 4. Melchor de Aguirre, Fachada principal de la Iglesia de Ntra. Sra. de los Dolores, 1686-1699. Autor: JADG. 
contenedoras de profusa hojarasca, junto con la iconografía alusiva a la dedicación del templo ${ }^{52}$.

El segundo cuerpo de esta fachada, se corresponde con el plano celestial. Una gruesa moldura escalonada lo diferencia del expuesto en el párrafo precedente. Aquí se alude a una vida que es real, fértil y eterna, de modo que la decoración se torna más abundante, sin salirse demasiado del racionalismo tectónico que caracteriza a Aguirre. Es también el plano de lo inextinguible, por lo que predominan el círculo y la curva sobre la línea recta. En las calles laterales aparecen las acanaladuras en los fustes, o el almohadillado de los sillares que se miran en sus homólogos renacentistas presentes en el Palacio de Carlos $V$. Pero lo más significativo de todo el conjunto es la original y novedosa introducción de un gran rosetón pétreo circundando el óculo del cuerpo central. Con sus ocho radios, semeja querer mirarse en las ruedas que contenían los crismones medievales, así como en la geometría de la figura astrológica de la Rosa Cósmica, que pone en relación a los opuestos, el Cielo y el infierno, el bien y el mal, tomando como centro a la única criatura que se ha insertado plenamente en todas estas dimensiones para redimir a aquellas que estaban afectadas por el pecado: Jesucristo. Pero este gran rosetón queda también inserto dentro de un cuadrado, rememorando una vez más los planteamientos renacentistas de la planta del Palacio de Carlos $V$, que contempla el círculo encerrado en el cuadrado como símbolo de la plenitud del Universo ${ }^{53}$. Es, en definitiva, este elemento, la parte visible al exterior de un gran ostensorio eminentemente simbólico, tras cuyo óculo se encuentra la que, para el cristianismo, es la clave de todos los tiempos y la unión física y real con la divinidad: Cristo hecho Eucaristía. Finalmente, el conjunto quedaba rematado por un friso corrido, coronado por una gran cruz marmórea que sobresalía entre flameros pétreos sobre podio, encajado entre las dos torres.

En lo que respecta a la portada lateral, ésta constituye un nuevo ejemplo significativo del talante ecléctico que configuró la proyección artística de Melchor de Aguirre. Al modo en que sucedía en el templo de la Merced Descalza, se siguen los planteamientos de Alonso Cano para la fachada principal de la Catedral ${ }^{54}$. De este modo, opta por cegar la luz de un esbelto arco de medio punto, sobre el que inserta los módulos de la portada propiamente dicha. El piso superior queda reservado para un luneto con la rosca almohadillada y originariamente reservado para la heráldica propia de la congregación. Le sigue un piso central, ya sí conservado en su totalidad, con un gran vano rectangular custodiado por columnas pareadas hexagonales, cuyos capiteles se miran en el orden corintio.

Por último, existe una puerta de acceso de medio punto, sobre la que se desarrolla un interesante friso moldurado mixtilíneo, recorrido en su centro por las cuentas de un gran rosario pétreo. En la parte central se genera una tarja sobre la que se muestra el relieve de La Virgen de los Dolores coronada por ángeles, tema que sin duda se inspira en aquel otro mencionado de la portada de la Capilla Salizanes. Por su parte, las columnas pareadas que orlan el arco de acceso al templo son nuevamente hexagonales, pero en su fuste se ornan con motivos de candelieri similares a aque-

\footnotetext{
52 APRG: Libro de Crónicas, T. II, p. 339.

53 ROLDÁN MEDINA, F.J. “Arquitectura y métrica en la planta circular del Palacio de Carlos V”, en Seminario "La planta circular en la arquitectura civil del Renacimiento. De la Casa de Mantegna al Palacio de Carlos $V$ ", Escuela de la Alhambra, Granada, 10 de octubre de 2014.

54 RODRÍGEZ G. DE CEBALlOS, A. “Alonso Cano, arquitecto artista”, Archivo Español de Arte, n 296 (2001), pp. $375-391$.
} 


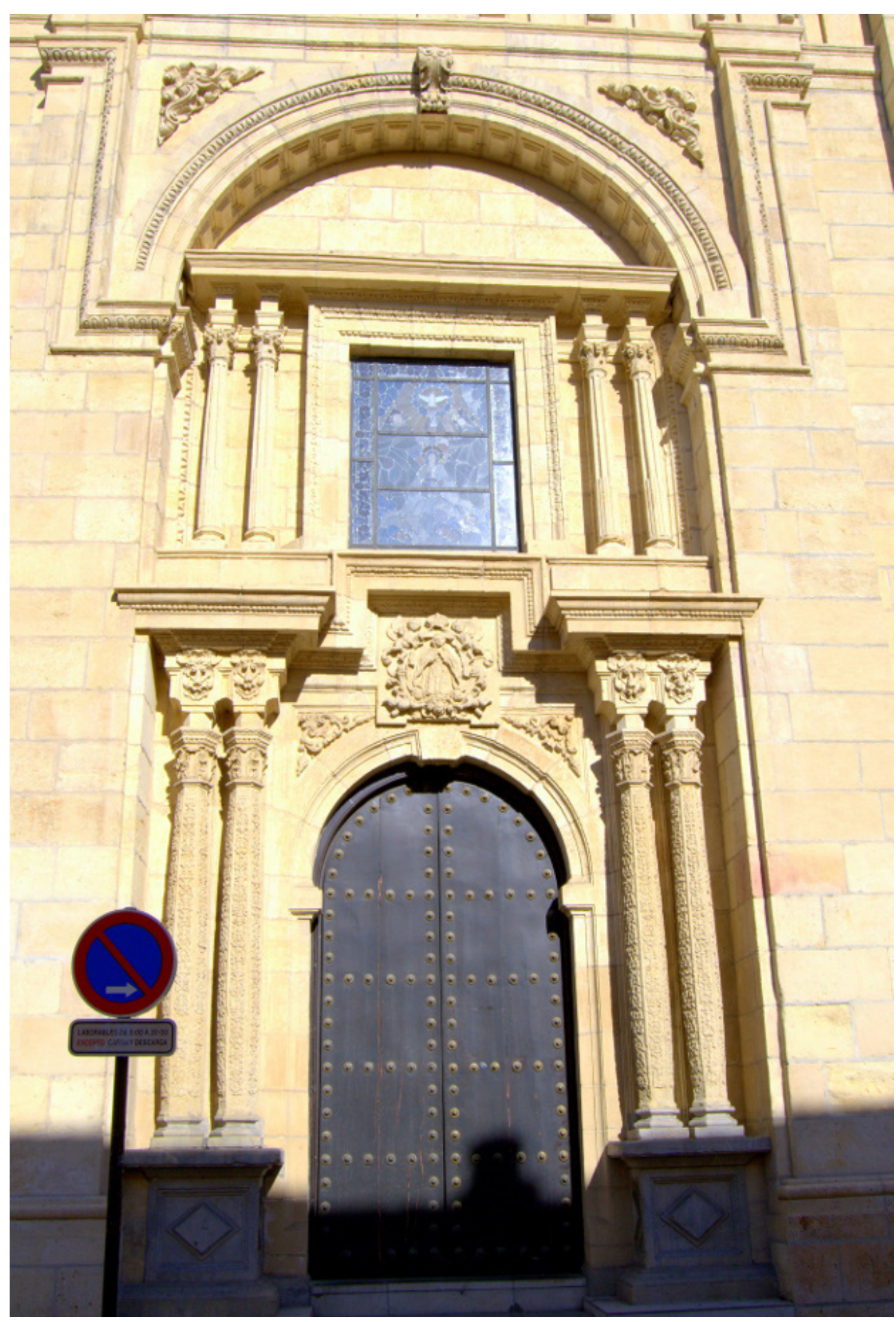

Figura 5. Melchor de Aguirre y Alfonso Castillo, Portada lateral de la Iglesia de Ntra. Sra. de los Dolores, 1686-1717. Autor: JADG. 
llos presentes en las portadas renacentistas de la Catedral de Granada. Las cuatro columnas se yerguen sobre un podio compartido por pares, al tiempo que, con sus capiteles corintios, sostienen un doble cimacio igualmente arcaizante y decorado con ovas, sobre el que, a su vez, se apoya un ábaco mixtilíneo decorado con placas recortadas y mascarones vegetales.

Todo parece indicar que, durante un lustro, Melchor de Aguirre dedicó la totalidad de su tiempo a culminar los proyectos inconclusos de Granados de la Barrera y, sobre todo, al desarrollo de las complejas y originales trazas de la Iglesia de Ntra. Sra. de los Dolores. Sin lugar a dudas, los acontecimientos posteriores apuntan a que Aguirre pudo alcanzar los objetivos esperados con sus ofrecimientos para obtener a toda costa la dirección y diseño de esta obra de envergadura. Así es que, en el año 1689, el trinitario fray Alonso Bernardo de los Ríos, arzobispo de Granada, decidido a avanzar en la medida de lo posible en las más que ralentizadas obras de la Catedral, pone sus ojos en la pericia y reputación de Melchor de Aguirre. De esta forma, el 16 de septiembre, Aguirre se convierte, junto con el madrileño Teodoro de Árdemans, en el nuevo Maestro Mayor Honorífico de las obras del templo catedralicio, cargo que ejercerá ya en solitario y hasta su muerte, con la renuncia y marcha de este último a la Corte en $1692^{55}$.

Entre tanto, Aguirre se había erigido como una auténtica autoridad consultiva en materia de arquitectura en Granada, de manera que un año antes inspeccionaba y daba su opinión sobre las obras que se estaban llevando a cabo en el Colegio de San Pablo de los jesuitas ${ }^{56}$, así como en las bóvedas de la Capilla Real ${ }^{57}$ que le permitirían realizar un estudio más profundo del sistema gótico de nervaduras, que ya había iniciado en la Iglesia de Santo Domingo y que trasladaría posteriormente a sus trabajos de abovedamiento para los templos catedralicio y oratoriano.

Empero, nunca abandonaría Aguirre sus trabajos como maestro de cantería puesto al servicio de las disposiciones que las órdenes religiosas le exigían como sus principales clientes. Así, en 1691 es posible asistir a la intervención del cantero y arquitecto en las obras de ampliación de la Iglesia de Ntra. Sra. de Gracia de la Trinidad Descalza, bajo las trazas y supervisión del fraile Sebastián de San Josés8. En esta ocasión, parece que la participación de Aguirre se limitó estrictamente al levantamiento de la portada central del templo, la cual resulta un excelente trabajo de cantería en piedra gris de Sierra Elvira, con elementos identitarios de la producción aguirreana, tales como las medias pilastras, el remate mediante un sobresaliente moldurón sobre el que se apoya un frontón partido, o la apertura del vano en una gran placa recortada que se desdobla en los ángulos superiores. Dada la similitud de rasgos estilísticos y de soporte, parecen coincidir temporalmente con esta última y en la misma urbe granadina, la portada de la Iglesia del Convento de la Madre de Dios de las Comendadoras de Santiago, así como las portadas interiores del claustro del

\footnotetext{
GILA MEDINA, L. Ob. cit., T. I, pp. 194-202.

56 RODRÍGEZ G. DE CEBALLOS, A. Bartolomé de Bustamante y los orígenes de la arquitectura jesuitica en España, Institutum Historicum, Roma, 1967, p. 186.

57 GALlEGO Y BURÍN, A. El Barroco granadino, Comares, Granada, 1987, p. 38 y ss.

58 Archivo Histórico Diocesano de Granada [en adelante: AHDG]: Documentación sobre el contrato y obras del convento de trinitarios descalzos, 1680-1692, caja 92-R, s.n. Instituto Gómez Moreno: Conventos. Libro CV, fol. 106v: "La portada del templo se hizo el año de 1691 por Melchor de Aguirre, Maestro mayor de la Santa Iglesia de Granada, uno de los primeros artífices que tiene hoy España”. [apunte copiado por Manuel Gómez Moreno a finales del siglo XIX de los libros capitulares de los trinitarios.
} 
Convento de San Antón, recientemente atribuidas al maestro por el profesor GómezMoreno Calera ${ }^{59}$.

Por las mismas fechas, atiende el encargo de realización del retablo mayor para el santuario de la patrona de la villa de Cabra, la Virgen de la Sierra. Para esta nueva obra, Aguirre repite una vez más su conocido esquema sobre el que levanta los retablos anteriormente descritos, aunque quizás el peso de la memoria de Granados de la Barrera en los principales templos egabrenses le hace recuperar la incorporación de algunos elementos por él abandonados, tales como la presencia de columnas salomónicas de fuste en mármol negro en las entrecalles, o la integración de la policromía en dorado para algunos elementos menores como los capiteles, las basas o los mascarones vegetales. De nuevo, el cromatismo habitual del mármol en tonos rojo, negro y gris, juega con el rigor de los planteamientos en torno al arco triunfal central, la placa recortada como elemento modulador, o el luneto del ático. Como novedad, para este retablo el taller de Aguirre se encarga igualmente de la confección de las demás esculturas que, lamentablemente, se hacen un trabajo algo torpe en cuanto a proporción y naturalismo se refiere, pero que se presentan como una propuesta interesante y poco usual en el entorno sobre la praxis de la escultura en piedra policromada; así es posible identificar un San José con el Niño y un San Joaquín para presidir las dos calles laterales del cuerpo central, algunos Ángeles en las enjutas y tarjas, el Espíritu Santo en la clave del arco del camarín, y el Padre Eterno, como siempre, en actitud bendecidora y asomándose desde ese tondo que actúa a la manera de rompimiento celeste.

Volviendo de nuevo la mirada hacia Granada, el arzobispo fray Bernardo de los Ríos vuelve a depositar su confianza en el juicio de Aguirre. Así en 1692 y dentro de los trabajos de la Catedral, el arquitecto consigue imponer su racionalismo tectónico ante la opinión del Cabildo Catedralicio, el cual le autoriza para proceder con su iniciativa de modificación del proyecto original de Alonso Cano para la fachada principal del templo metropolitano ${ }^{60}$. De este modo, primeramente la Fachada de la Encarnación era concebida como un colosal arco de triunfo clásico, quedando a la vista el perfil curvilíneo de su triple arcada, mayor la central que las laterales, y coronadas por un pétreo apostolado. Por su parte, Aguirre logra introducir la adición, a modo de remate, de un friso corrido, coronado por una gran cruz central y flameros sobre podios, como se vio en el proyecto para la Iglesia de Ntra. Sra. de los Dolores, con lo que se transformó considerablemente la impresión generada por el alzado catedralicio. Además, basándose en sus experiencias en la Corte, inspiradas directamente por el Barroco romano, impone la demolición del antiguo Colegio de San Miguel, de modo que ante la fachada catedralicia se abre el espacio de una plaza que posibilite una más grandilocuente presentación del conjunto arquitectónico ${ }^{61}$.

De otro lado, el mismo prelado granadino, cercano ya a la fecha de su muerte, que tendrá lugar el 5 de octubre, a comienzos de ese mismo año consigue recuperarse de una larga enfermedad, por lo que decide costear la erección de una ermita dedicada a su principal devoción: san Juan Bautista. Es así como, en una parcela del lugar denominado como Eras de Cristo, encomienda a Melchor de Aguirre el diseño y di-

59 Cfr. GÓMEZ-MORENO CALERA, J.M. "La arquitectura”, en El Convento de San Antonio Abad de Granada, Capuchinos Editorial, Madrid, 2017, T. II.

60 GILA MEDINA, L. Ob. cit., T. I, pp. 194-202.

61 Ibidem. 
rección de las obras de la Ermita de San Juan de Letrán, las cuales transcurren en un breve espacio de tiempo ${ }^{62}$. Se trata de una obra bastante sencilla, actualmente muy desfigurada al exterior, realizada en ladrillo en su mayor parte, con planta de salón de tres naves. Como cabía esperar, la portada, de extrema austeridad, es dignificada por el autor de la traza al levantarla con sillares de piedra franca y dentro de una concepción habitual de tres arcadas demarcadas por pilastras, sin mayor presencia ornamental. Igualmente sencillo, se presenta el segundo cuerpo de la fachada, ya realizado en ladrillo visto, con idéntica presencia de pilastras como elemento modulador y un vano rectangular ocupando el espacio central, mientras que en los laterales emergen en piedra dos blasones con la heráldica episcopal, sobre el fondo en azul de dos simples placas recortadas que se desdoblan en sus cuatro ángulos.

Al interior, el retablo mayor, aunque sin documentar y realizado en madera policromada, parece seguir una clara traza aguirreana basada en los esquemas ya conocidos dentro de la praxis retablística del arquitecto. Sin embargo, existen algunas variantes interesantes, ya que el luneto superior esta vez carece de la presencia del Padre Eterno, para albergar tres lienzos: el central es rectangular y alusivo a la fundación de la basílica lateranense, y los semilunetos laterales se presentan con los temas de la Imposición de la casulla a san Ildefonso y de la Aparición de la Virgen con el Niño a San Juan de la Cruz. También, al carecer de espacio para un camarín y al ser habitualmente limitado el margen para la disposición de imaginería en los retablos de Aguirre, la misma calle central, sobre la que se abre el usual arco cegado de medio punto, alberga una estructura cuya parte inferior no es sino un manifestador, sobre el que se yergue el pseudocamarín de Ntra. Sra. de la Consolacion, que a su vez sirve de pedestal para el santo titular del templo, aunque esta triple estructura parece ser una incorporación posterior de la primera mitad de siglo XVIII. Las dos calles laterales se reservan para las tallas de San Pedro y de San Pablo. Por lo demás, la huella aguirreana es más que evidente, con la presencia ornamental de placas y tarjas, junto con una policromía que busca imitar el jaspeado habitual de sus retablos.

Entre 1693 y 1694, Melchor de Aguirre se hará cargo de dos nuevos e interesantes proyectos en la ciudad de Antequera, lo que le permite retornar al ámbito malagueño con todo el bagaje acumulado. En primer lugar, es posible encontrar el levantamiento de la iglesia de los jesuitas, dedicada a Ntra. Sra. de Loreto ${ }^{63}$. Lo más conspicuo del proyecto de Aguirre, junto con la traza arquitectónica de piedra franca, es la fachada principal, de acusada verticalidad, al modo en que había usado para los oratorianos granadinos, aunque finalmente inconclusa. Para su levantamiento, el maestro da un paso más en la preparación del espacio previo mediante un arco de medio punto de considerable profundidad con la rosca almohadillada.

En intención, Aguirre, pese a coronar el conjunto con seis pequeños contrafuertes que hacen que la estructura de la nave descanse parcialmente sobre la cimentación de la fachada, lo que pretende aportar no es sino la solución canesca de cegar el arco frontal de la base para insertar en él la portada, la cual, por otro lado, resulta bastante sencilla. Ha sido erigida en piedra de Cabra, con dos pirámides curvadas en las enjutas del arco de acceso, motivo que no se repetía desde la Capilla Salizanes. Dicho arco se enmarca dentro de una gran placa recortada que, como siempre, se desdobla en sus vértices superiores, resaltando decorativamente los puntos angulares. Centra

CRUZ CABRERA, J.P. Ob. cit., p. 146.

63 GÓMEZ GARCÍA, M.C. y MARTÍN VERGARA, J.M. Ob. cit., pp. 95-111 


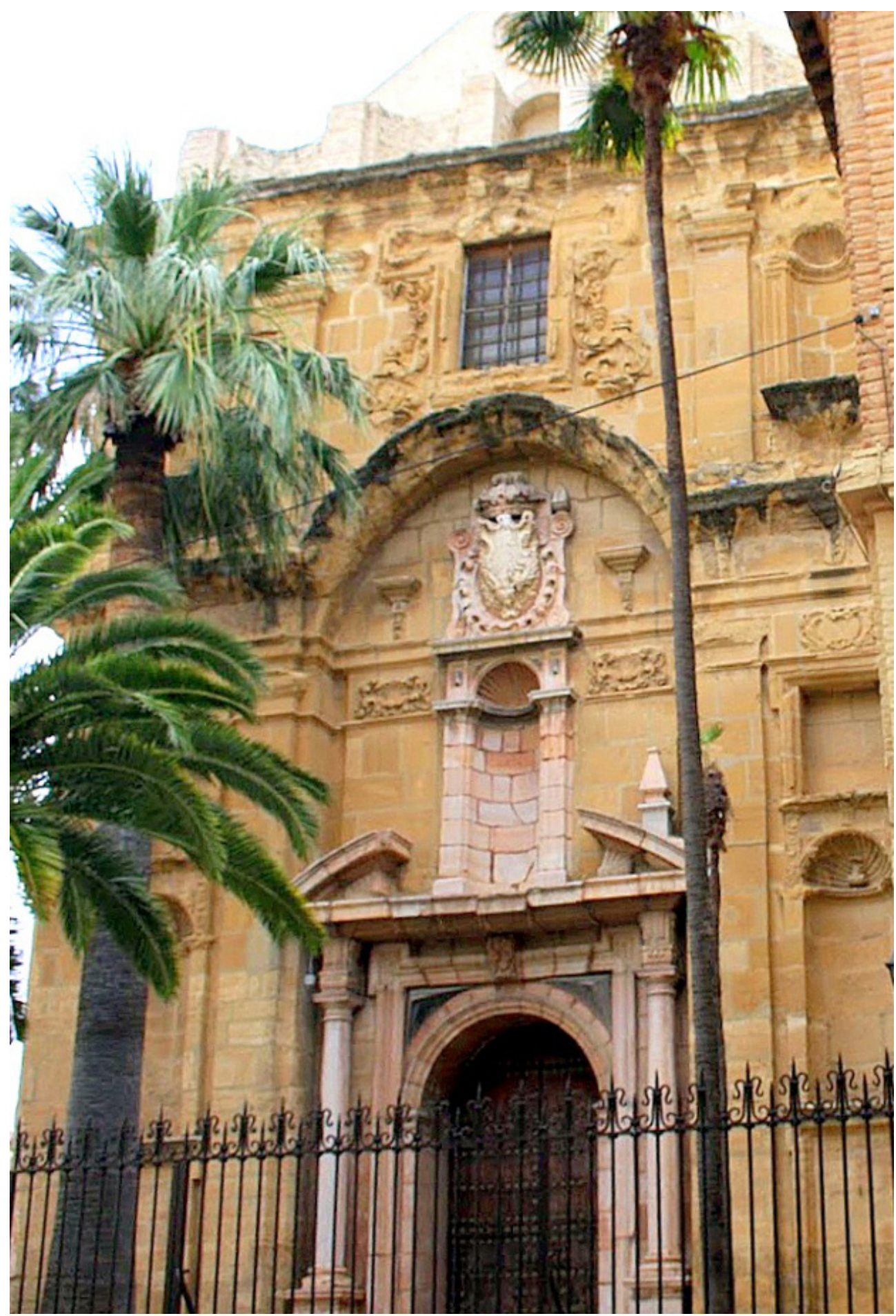

Figura 6. Melchor de Aguirre e Ignacio de Urceta, Fachada de la Iglesia de Loreto, Antequera, 1693-1699. Autor: JADG. 
el arco un mascarón vegetal, a la par que queda custodiado por dos columnas sobre podio. Una moldura de escasa prominencia constituye, a un tiempo, la génesis del frontón avenerado y partido del que surge una simple hornacina, coronada originalmente por el emblema jesuítico, que fue sustituido por el escudo de Carlos III tras la expulsión de la Compañía en 1767. La portada se inserta dentro del interesante conjunto de la fachada bipartita, correspondiéndose el primer cuerpo con el espacio de la portada en su calle central, mientras que las dos laterales, custodiadas por pilastras de orden gigante, albergan vanos cuadrangulares y nichos. Al igual sucede en el cuerpo superior, considerablemente más estrecho que el primero, y donde el cuerpo central queda ocupado por una ventana rectangular, inserta en un marco de hojarasca algo más torpe en la resolución formal y posiblemente posterior a la intervención de Aguirre.

La segunda empresa del arquitecto en Antequera se sitúa nuevamente en la fachada de la pequeña Iglesia de San Juan de Dios ${ }^{64}$. Se trata de un proyecto algo diferente y mucho más austero en recursos, que lleva a cabo con la ayuda de sus discípulos Francisco del Castillo e Ignacio de Urceta. El conjunto queda coronado por una gran espadaña de dos cuerpos diferenciados por un moldurón, rematados en un frontón curvo y ornados con flameros en sus extremos, por lo que se hace vinculable asimismo a la autoría de Aguirre. Por lo demás, la fachada consta de un único tramo, flanqueado por el orden gigante. La parte superior cuenta con dos vanos cuadrados y desdoblados en sus esquinas, centrados por una gran tarja mixtilínea contenedora del emblema de la Orden Hospitalaria, que replica los modelos de tarjas empleados por Francisco Bautista en la fachada de la toledana Iglesia de San Ildefonso. Por su parte, la portada en sentido estricto, de nuevo adquiere los tonos rojizos del mármol egabrense y demuestra una mayor libertad compositiva de la mano de Aguirre, al poderse contemplar una abstracción geométrica que funde los elementos tectónicos al modo ya descrito de la portada de la Capilla Salizanes, aunque mucho más simplificado en la multiplicación de elementos. Nuevamente, las enjutas del arco se completan con pirámides de mármol gris, mientras que el nicho que contiene la efigie de San Juan de Dios se remata en un frontón curvo, circundado por piramidones coronados por bolas de corte herreriano.

El de 1694 es también el año en que recibe el encargo de otros trabajos de relevancia, tales como el abovedamiento de las naves central y del Evangelio de la $\mathrm{Ca}$ tedral de Granada ${ }^{65}$, siguiendo los modelos de bóveda de nervaduras ya expuestos anteriormente, ahora con el patrocinio del nuevo arzobispo granadino, don Martín de Ascargorta, principal impulsor de las obras del templo metropolitano. Asimismo, se hace cargo de dar la sencillísima traza para la hornacina con que se remata la portada del Colegio de la Purísima de Cabra, iniciada por su maestro, José Granados de la Barrera ${ }^{66}$. Por su parte, los trinitarios descalzos de Granada vuelven a confiar en su maestría en el ámbito de la cantería, para encomendarle el engrandecimiento de su retablo mayor con la incorporación de un pequeño templete en piedra de Cabra, con el que orlar la embocadura cuadrangular del nicho de Ntra. Sra. de Fracia $^{67}$. La

\footnotetext{
64 OLMEDO SÁNCHEZ, Y.V. "Singularidad y proyección de la arquitectura barroca cordobesa", PEINADO GUZMÁN, J.A. y RODRÍGUEZ MIRANDA, M.A. (coord.) Nuevas perspectivas sobre el Barroco Andaluz. Arte, Tradición, Ornato y Símbolo, Asociación "Hurtado Izquierdo", 2015, pp. 174-194.

65 GILA MEDINA, L. Ob. cit., T. I, pp. 194-202.

66 MORENO HURTADO, A. Ob. cit., p. 501.

${ }_{67}$ RIVAS CARMONA, J. “Los tabernáculos del Barroco andaluz”, Imafronte, nn. 3-5 (1987-1989), pp. 157-186.
} 


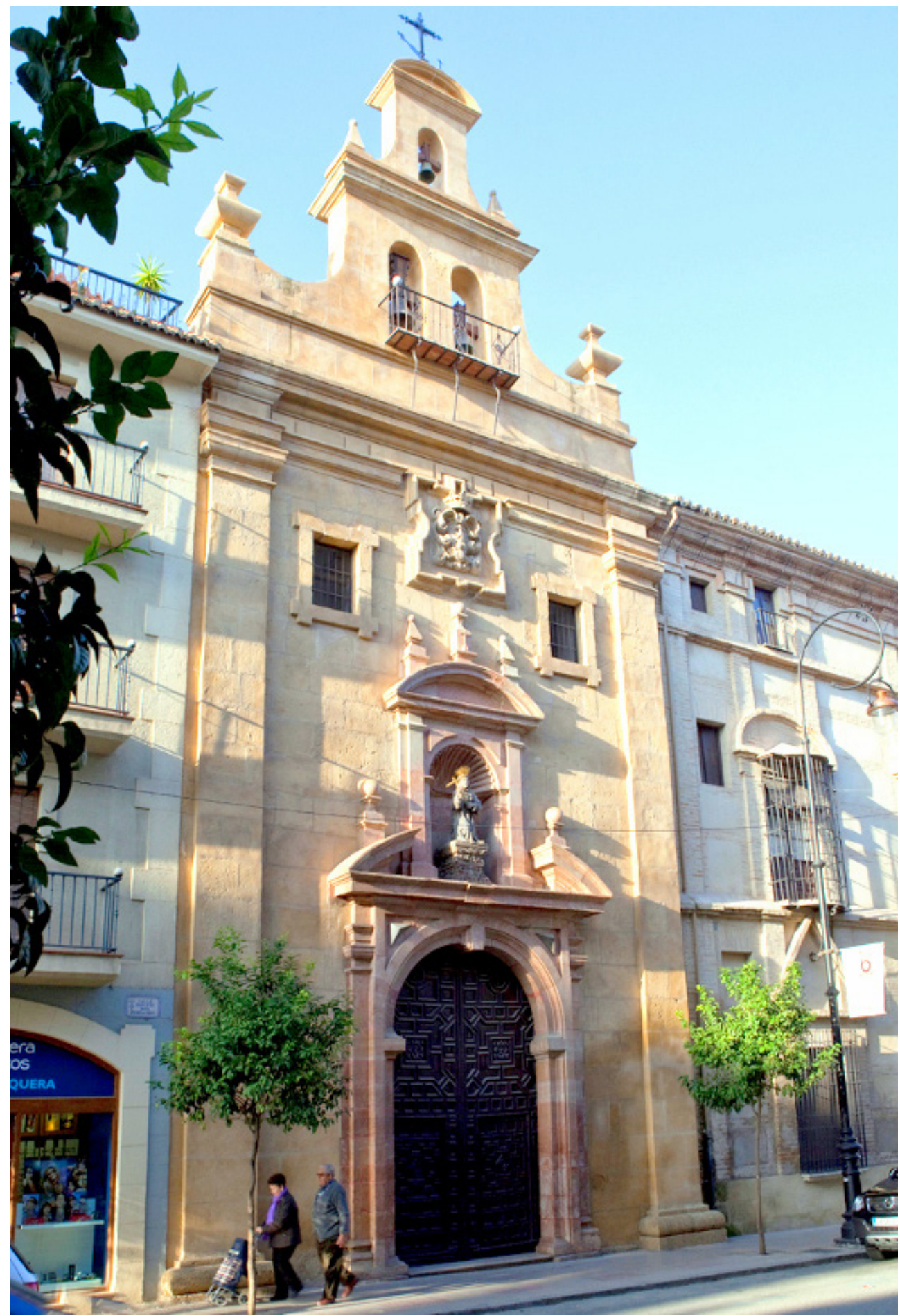

Figura 7. Melchor de Aguirre, Francisco del Castillo e Ignacio de Urceta, Fachada de la Iglesia del Hospital de San Juan de Dios, Antequera, 1694-1696. 
estructura se limita a un sencillo juego de molduraciones, esquematizaciones geométricas y placas recortadas, al que se añaden dos columnas salomónicas de fuste negro y blanco capitel.

Por las mismas fechas se documenta su participación en la traza de los dos primeros cuerpos del antiguo retablo mayor de la Iglesia de San Lorenzo de Córdoba, que será culminado por su joven discípulo, el lucentino Francisco Hurtado Izquierdo, junto con el ensamblador Juan Leiva en $1696^{68}$. Se trata del segundo ejemplo de retablo aguirreano en madera, en este caso sobredorada, al que es posible aludir en la trayectoria del arquitecto. No obstante, la concepción de este nuevo encargo resulta demasiado barroquizante en lo ornamental para lo que el autor acostumbra en este tipo de encargos; eso sí, la estructura responde a los patrones canescos habituales, de tres calles perfectamente delimitadas y dos cuerpos a los que se añade un potente ático que, en esta ocasión, es obra de Hurtado.

A excepción de la imagen del santo titular del templo, que ocupa el nicho central del segundo piso, el soporte iconográfico de este retablo es eminentemente pictórico, lo que implica a Aguirre en una mayor potenciación del relieve decorativo. De esta forma, las pinturas se insertan en placas recortadas que copan toda la calle lateral pero que se contraen en sus ángulos generando una reducida cartela vegetal, lejos de desarrollarse en el desdoblamiento habitual, cosa que sí sucede en la calle central del primer cuerpo, la cual contiene el medio punto que alberga un interesante tabernáculo. Este último elemento, supone un relevante ensayo de lo que, a mayor escala, Aguirre se encuentra ideando para la cabecera de la granadina Iglesia de Santo Domingo. Con él, genera la impronta de un potente templo en miniatura de planta centralizada, basado en una traza ochavada a la que la adición de columnillas con podio y ábaco dota de un perfil mixtilíneo dinamizante. Por lo demás, se prefiere el orden corintio con exorno vegetal en la parte inferior de los fustes, se añaden volutas en los arranques del tambor, donde los vanos son ocupados por pinturas con el apostolado, las columnillas se geminan y nace de ellas un cupulín de gallones.

De nuevo, junto con Hurtado Izquierdo, su pupilo más aventajado, intervendrá en la traza y levantamiento del retablo mayor de San Pedro de Alcántara en Córdoba, realizado al tiempo del anterior entre los años 1695 y $1696^{69}$. Del mismo modo, la participación de Aguirre se limita a la intervención en el primer cuerpo, el cual configura con la estructura tripartita habitual, presidida por un arco de medio punto. Sin embargo, en este caso la ornamentación se vuelve algo más parca, prefiriendo jugar con el cromatismo de los mármoles y el brillo del pulimento, prescindiendo de la presencia de tarjas y placas recortadas. El interés, otra vez, parece haberse querido concentrar en la experiencia del monumental conjunto que supone el templete de la calle central. Este elemento se divide en dos cuerpos, generando el inferior, correspondiente al sagrario, una impronta maciza e infranqueable en rojo egabrense de planta escalonada. Entre tanto, el espacio del manifiesto es un suntuoso templete, con columnas salomónicas pareadas en mármol negro y motivos de sobra conocidos, como las pirámides en las enjutas de la portadilla, la prominencia de los moldurones o el remate del cupulín con un flamero sobre podio, circundando todo ello una estructura ochavada que quiere ser una barroquización contenida del racionalismo con

\footnotetext{
68 RAYA RAYA, M.A. "Francisco Hurtado Izquierdo y su proyección en el arte andaluz del siglo XVIII", Actas del Congreso Internacional Andalucía Barroca, Junta de Andalucía, Sevilla, 2009, pp. 191- 208. 
que Juan de Herrera revistió a su templete escurialense del Patio de los Evangelistas.

Empero, el templete aguirreano juega con las luces y las sobras, con la agresividad de los elementos salientes que parecen querer desafiar a la verticalidad que predomina en las obras de este maestro. El cromatismo de los jaspes y la victoria de la curva sobre la recta en el plano ascendente se hallan presentes, como en ninguna otra creación, en los tabernáculos de Melchor de Aguirre. Así lo replica y engrandece en ese mismo año de 1695, cuando se hace cargo de las obras de la ampliación barroca de la cabecera de la Iglesia de Santo Domingo en Granada ${ }^{70}$, que jamás verá concluir, pero donde deja el diseño de un extraordinario tabernáculo que levantará mediando el siglo XVIII el también cantero y arquitecto, José de Bada, hijo de otro de sus grandes discípulos, Toribio de Bada, citado al comienzo de este trabajo.

La genial traza de Aguirre parece también clara en las obras de ampliación de la iglesia del Hospital del Corpus Christi, dirigidas por José Sánchez de Rueda en la misma Capital Nazarí ${ }^{71}$. Igualmente, aquí se vale del contrastado lenguaje de la piedra negra y blanca, para levantar un tabernáculo mucho más contenido en dimensiones, pero de idéntica exquisitez y de mayor proyección horizontal. Tarjas, pirámides y bolas herrerianas vuelven a reproducirse en la mitad superior de este trabajo, al igual que en el recorrido del zócalo de mármol rojo con que se recubre el perfil absidial de la capilla mayor y rodea el expresado templete, donde inserta nichos en que la piedra blanca adquiere forma angélica, para generar un iconográfico coro celestial que queda en continua alabanza del sacramento eucarístico que encierra el tabernáculo.

Finalmente, en los albores del año 1696, Melchor de Aguirre es nombrado Maestro Mayor de las obras de la ciudad palatina de la Alhambra, donde se hace cargo de dirigir los trabajos de rehabilitación de la Qubba Mayor ${ }^{72}$, lo que le permite entrar en contacto con los sistemas arquitectónicos y ornamentales del pasado nazarí. Es este aspecto el que, sin duda, le influye notablemente a la hora de dar una traza inicial para el estrellado ornato de un camarín para la efigie de Ntra. Sra. del Rosario, durante los enunciados proyectos de ampliación de la Iglesia de Santo Domingo. Así también, en 1697 recibe el encargo de cubrir las dos bóvedas menores del lado de la Epístola de la Catedral de Granada, proyecto que no logra culminar con la brevedad establecida, al sobrevenirle la muerte en su casa de la granadina collación de Santa Escolástica en la jornada del 19 de septiembre del expresado año ${ }^{73}$. Con su deceso, reclaman sus bienes, argumentando pobreza de solemnidad, Melchor e Isabel, sus dos hijos menores, fruto de la relación extramatrimonial que mantuvo en los últimos años de su vida con la egabrense Francisca Bonilla, sin que le sea conocido matrimonio alguno ni más descendencia ${ }^{74}$. Quedan como continuadores de sus obras inconclusas Juan de la Borda, Francisco Zurita e Ignacio de Urceta.

RIVAS CARMONA, J. Ob. cit., pp. 157-186.

71 BARRIOS ROZÚA, J.M. "La arquitectura del pleno Barroco en Granada: el Hospital del Corpus Christi", Archivo Español de Arte, no 84 (2011), pp. 1-24.

72 Archivo del Patronato de la Alhambra y Generalife: Nombramiento de Salvador Martín como maestro de albañilería para reconocer el estado en que habian quedado las obras por la muerte de Melchor de Aguirre, 1697, sig. L-152.

73 GILA MEDINA, L. Ob. cit., T. I, p. 195.

74 Ibidem. 


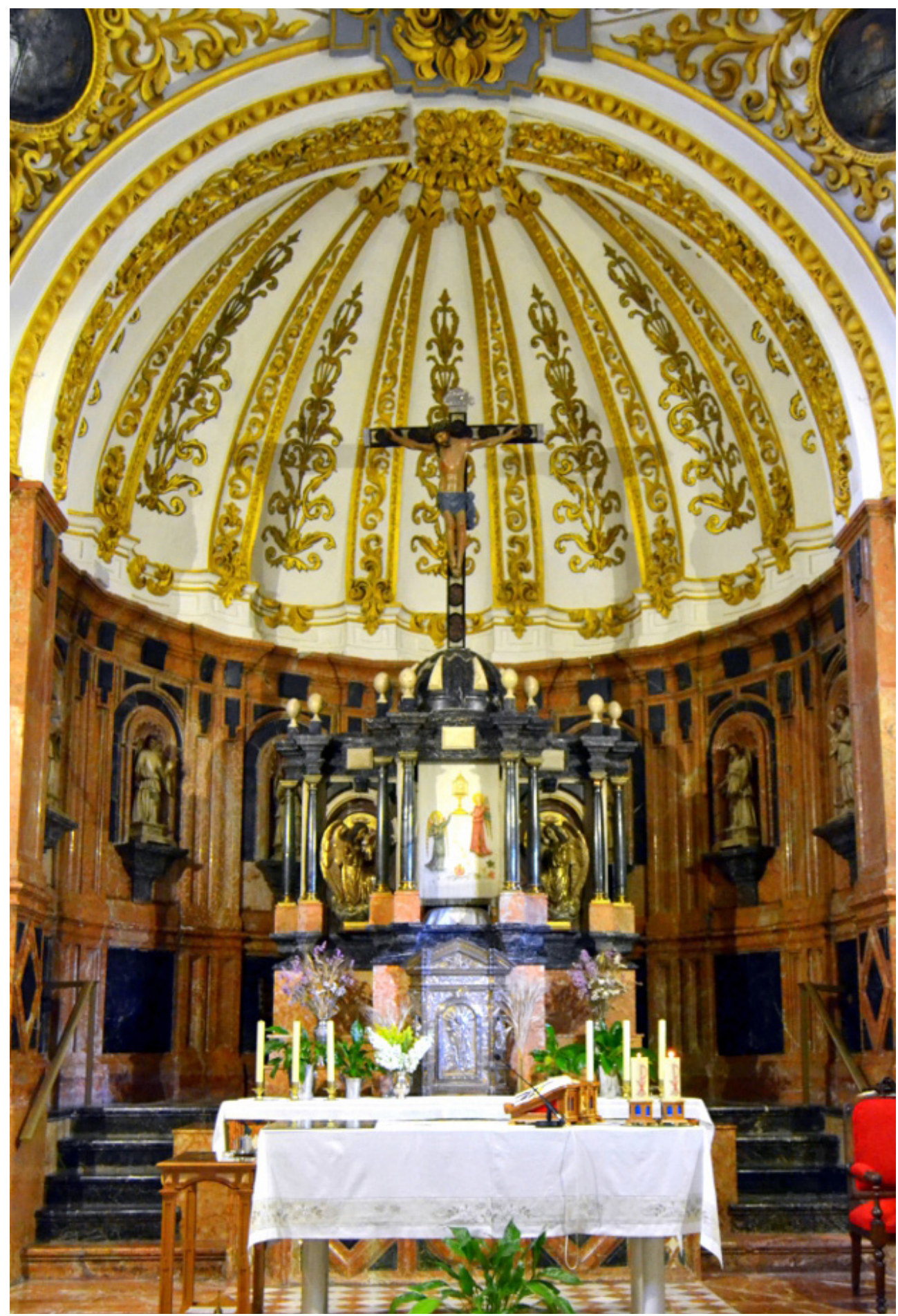

Figura 8. Melchor de Aguirre y taller, Capilla Mayor del Hospital del Corpus Christi, Granada, h. 1695. Autor: JADG. 


\section{Conclusiones}

A lo largo de este pequeño estudio, han sido desgranados y analizados los rasgos y elementos que caracterizan al corpus de retablos y portadas de Melchor de Aguirre. Por tanto, el lector de estas páginas se ha encontrado con una visión de Aguirre, más próxima al género de la cantería que al de la arquitectura, salvo por aquellos elementos tectónicos con que soluciona problemas de elevación de este tipo de estructuras, las cuales, en numerosos casos, se han constituido en una sola entidad con los elementos netamente arquitectónicos.

El maestro cantero prefiere el corte recto y depurado como sello identitario en sus creaciones, relegando la ornamentación como un mero complemento que puntualmente puede y debe tener cabida entre el rigor y la monumentalidad del elemento arquitectónico. Por ello, sus primitivas estructuras no tectónicas, como los púlpitos de la Catedral de Málaga pueden resultar insulsos, pero potentes en el rigor del corte de la piedra, con el que el Arte Barroco adquiere un último sentido en sus derroteros finales por el ámbito andaluz.

Empero, el talento aguirreano, pese a contar con una formación y una protección iniciales con las que pudo acceder a trabajos de mérito, quedaría en un principio copado por la sombra proyectada por la no menos conspicua técnica de Granados, que para él supondría su impulso definitivo con la asimilación de los modelos canescos añadidos a la experiencia cortesana previa. Estas connotaciones estarían ya presentes en la traza de los retablos egabrenses que la vida le dio la oportunidad de hacer y rehacer, pero sobre todo en los grandes encargos que respondían a las miras del arzobispo Salizanes, así como de las órdenes religiosas de Granada y Antequera. Con el rigor exterior del muro, combinó la exuberante decoración que brotaba al interior de una intangible fuente de vida. En todos estos trabajos, a la aplicación de lo aprendido sucedió la exploración de las posibilidades eclécticas en la arquitectura de la portada, del retablo y, respondiendo a aquello que estaba por venir, del monumental tabernáculo, sobre todo lo cual se apoyarán posteriores escenografías, como las que caracterizan a las intervenciones de Hurtado Izquierdo en las capillas eucarísticas de las cartujas de Granada y El Paular, entre otras.

La genialidad del cantero y arquitecto Melchor de Aguirre marca el punto de inflexión que conduce al Barroco de Andalucía desde el clasicismo dinámico a la integración de otros estilos artísticos, lo que conlleva a la inevitable gestación de nuevas formas. Es así como queda sembrada la semilla para que sus grandes sucesores, fundamentalmente Francisco Hurtado Izquierdo y José de Bada sean los protagonistas de ese último Barroco engendrado entre golpes de cantería y la admiración por la belleza del soporte pétreo y sus posibilidades. Se evidencia cómo el campo de los retablos y las portadas han sido elevados a su más alta dignificación, para que, en la medida de lo posible, dejen de ser elementos de cariz casi postizo, para integrarse en el conjunto edilicio como un elemento más del trabajo arquitectónico, donde el más mínimo elemento ha sido tocado con una profunda intencionalidad simbólica, fruto del renovador ingenio aguirreano. 